In L.J. Rogers \& M. Andrew (Eds.), Comparative Vertebrate Lateralization (pp. 306-362).

Cambridge, LTV: Cambridge University Press.

9

\section{Posture and Laterality in Human and Non- human Primates: Asymmetries in Maternal Handling and the Infant's Early Motor Asymmetries}

E. DAMEROSE AND J. VAUCLAIR

\subsection{Introduction}

This chapter is concerned with the question of the relations and possible influences of environmental factors on the establishment of patterns of manual lateralization in human and non-human primates. More specifically, we are interested in the relation between maternal postures and laterality in nonhuman primates (e.g. bias in cradling behaviour and hand preference of the mother) and the development of patterns of manual preferences in infants. In order to understand fully the many ways in which these variables could interact, we first review the evidence of postural biases in human adults when cradling and carrying their offspring. Next, we examine the divergent hypotheses advanced to explain the observed biases. The same is then done for non-human primates. A second part of our chapter (see Section 9.3) describes the different asymmetric patterns observed during the development of the infant concerning head turning, nipple preference, etc.in both human and non-human primates.

In a third part (see Section 9.4), we describe and compare the methods and definitions used by the different authors in their work. Then, we present the descriptions and definitions of behaviours that we are using in an ongoing study of Olive baboons (Papio anubis).

Our main goal is to contribute to understanding the phylogenetic origins of hand laterality in humans by examining some of its possible determinants in non-human primates. Despite numerous efforts to propose models and explanatory schemata of hand laterality in non-human primates (e.g. MacNeilage, Studdert-Kennedy and Lindblom, 1987; Fagot and Vauclair, 1991; Ward and Hopkins, 1993), this question is still largely unresolved. On the other hand, views of determinants of hand laterality in humans still fluctuate between genetically (e.g. Annett, 1985, 1995; Hopkins and
Posture and laterality in human and non-human primates

Rönnqvist, 1998) and environmentally based determination (e.g. Provins, 1997). A primate (non-human) model of hand preference is likely to advance our understanding greatly of human lateralization and its evolution. The interest in having a primate model is obvious. For example, if we were able to demonstrate that non-human primates exhibit the same cradling asymmetries as humans, we could better understand the respective roles of biological versus experiential/cultural factors in the causation of this phenomenon. Moreover, by attempting to relate postural biases of the mother to the hand biases of infants (in terms of manual preference), we should also be able to understand the importance of the maternal environment on the determination of the infant's biases and preferences.

Given that the main external agent acting on the foetus and then on the infant is the mother, it is necessary to consider in what ways the mother may determine the newborn's immediate environment and how her behaviour may affect the neonate's subsequent manual choices.

\subsection{Asymmetries in Cradling}

The first behaviour of interest is cradling. Cradling most often refers to the hand (and the arm) used by the mother to hold her infant. We will examine the available evidence in relation to asymmetrical biases in cradling first in human and then in non-human primate mothers.

\subsubsection{Human Studies}

The first published investigation examining the possible association between maternal behaviour and the infant's developing laterality was carried out by Salk (1960). This author studied cradling behaviour of the human mother. Casual observations of a mother rhesus monkey carried out by Salk (1960) revealed that this female held her newborn on the left side 40 times out of a total of 42 observations, frequently with the newborn's ear pressed against her heart. This finding prompted Salk to conduct observations on human mother-infant pairs. Salk found a left-side cradling bias at a population level in $80 \%$ of the observations, regardless of mother's handedness. This bias was spontaneous and without awareness on the part of the mother. Salk (1960) proposed that the heartbeat of the mother constituted a comforting stimulus to which the foetus was imprinted. In subsequent studies, Salk $(1962,1973)$ tried to establish whether the observed bias was an instinctive response evolved from a need on the part of the infant to continue to experience the maternal heartbeat rhythm or, alternatively, whether it was based on learning 
a familiar sensation during intrauterine life. In order to investigate what was the effect of the heartbeat sound on the infant, two groups of infant newborns were formed. In the experimental group, the infants were exposed to sounds identical to those produced by their mother's heartbeat, whereas in the control group, newborns were not exposed to these sounds. The results of the study showed an increase in body weight, without any change of food intake and a decrease of injuries and stress level; these effects were significantly greater in the experimental group than in the control group.

Following Salk's pioneering work, numerous studies have reported the same leftward maternal cradling in human populations (see references in Saling and Kaplan-Solms, 1989). Interestingly, this bias is in marked contrast to the usual rightward skew that seems to govern the actions directed by Homo sapiens on the environment. Moreover, this bias appears to represent a universal pattern in the human female. Indian as well as African mothers are reported to hold their infant with the left hand, even though some cultural variations during the transport of the infant have been described (Saling and Cooke, 1984). Contrary to the opinion advanced by Salk (1970), according to which early postpartum experience was critical for the emergence of the leftsided cradling preference, Saling and Tyson (1981) showed that almost $90 \%$ of nulliparous women spontaneously cradled a doll (which served as the 'infant', see Section 9.5.1.3) in the left arm. This asymmetrical pattern initially reported for infant holding was also present when mothers held their children (Richards and Finger, 1975). Indeed, left-side infant cradling appears to be characteristic of female behaviour. Thus, an analysis of 'family album' photographs revealed that it is primarily a behaviour of human females and not of males (Manning, 1991; Manning and Denman, 1994), although some 'contamination' between wives and husbands in holding habits cannot be excluded (Dagenbach, Harris and Fitzgerald, 1988).

\subsubsection{Eunctions of Left Cradling}

Several hypotheses have been proposed in order to explain the left bias of human mothers in cradling, and showing related behaviours (e.g. transport) towards their infants and children.

(a) The heartbeat hypothesis. One hypothesis is derived from Salk's (1962; and above) experiments with newborns exposed to a recorded normal adult heartbeat sound. The positive effect of the heartbeat on the decrease of crying and weight gain prompted Salk (1973) to conclude that the sound of the normal adult heartbeat had a soothing effect on the newborn. As a consequence, when the baby is held on the mother's left side, he/she receives soothing sensations from the mother's heartbeat. The mother's heartbeat is thus interpreted as an imprinting stimulus creating a low-anxiety situation that the mother will tend to repeat when holding her baby. This imprinted response to an innately determined releasing stimulus was, for Salk (1962), also present in the mother who tried to increase awareness of her own heartbeat. A similar explanation was suggested by Weiland (1964), who emphasized the role of the mother's heartbeat in relieving anxiety of both the infant and the adult.

(b) Lower threshold of the left side for tactile perception. An assumption of psychophysics is that the left side of the body has a lower threshold for tactile perception compared to the right side. This view was revived with a study by Weinstein (1963) who measured left and right female breast sensitivity and reported a greater sensitivity on the left that was apparently independent of handedness. Kaplan-Solmes and Saling (1988) tried to replicate this reported sensory asymmetry but failed to support Weinstein's finding of a lower pressure threshold for the left than for the right breast of females.

(c) The maternal emotion hypothesis. Weiland and Sperber (1970) asked females to hold a pillow against their chest and found no side preference. When the women were told to imagine that they were holding a threatened infant, most participants held the pillow on the left (see also Manning and Chamberlain, 1991). The authors concluded from their study that maternal emotions might influence cradling preferences. It is possible that the observed left lateral placement in response to anxiety serves to intensify heartbeat sensation. In this respect the present hypothesis is thus formally equivalent to that described above (under Section 9.2.1.1.a).

A view based on the predominant role of the right hemisphere in the control of emotional behaviour has been proposed by Manning and Chamberlain (1991). The hypothesis goes as follows: when a female participant cradles an infant on the left side of her body, the infant's face is located on the extreme left of the participant's visual field. Because of the organization of the visual pathway connecting the retina to the brain, the left part of the visual field connects the nasal retina to the right hemisphere (Corballis and Beale, 1976). Manning and Chamberlain (1991) directly tested the hypothesis that perception of an infant (or a life-sized doll) via the left eye would stimulate left-side cradling. In order to test this hypothesis directly two experiments were conducted, one with mothers and one with young females (from 6 to 16 years of age). Mothers had to pick up and carry their infants, while non-mothers had to pick up and carry a life-sized doll. Three groups were made within each population: (1) a left-eye occluded group (an opaque 
Table 9.1. Percentages of left cradling as a function of the population and group in Manning and Chamberlain's (1991) experiment

\begin{tabular}{lll}
\hline & Mother's cradling & Non-mother's cradling \\
\hline Left eye occluded & 40 & 60 \\
Right eye occluded & 69 & 72 \\
Control & 66 & 80 \\
\hline \hline
\end{tabular}

patch was placed over the participant's left eye); (2) a right-eye occluded group (similar procedure with the right eye); (3) a both eyes occluded group; and (4) a control group. Percentages of left or right cradling were recorded (see Table 9.1).

The results show clearly that occluding the right eye had no significant effect on left cradling biases. The results were similar in this condition and in the control condition (two eyes available), whereas occlusion of the left eye led to a frequency of left-side cradling which was significantly lower than that of the control group but not different from an expectation of $50 \%$ left side cradling.

From such differences in left cradling distributions, Manning and Chamberlain (1991) concluded that this bias had a twofold function: (1) it allows the mother to monitor her infant's well-being with her left visual field (thus facilitating the communication with her right cerebral hemisphere); and (2) it allows the infant to monitor the mother's emotional condition, given that the most expressive side (i.e. the left) of the mother is visible to him/her.

This appealing explanation of left cradling has, however, not been confirmed in the investigations conducted by Lucas, Turnbull and Kaplan-Solms (1993). No relation was found between cradling and the perception and expression of emotions. However, the methodology they chose (use of a population of non-mothers for carrying a doll and separate tests for evaluating asymmetries in expressing and producing emotions) precludes any direct comparison between the two studies.

A final approach needs to be mentioned. Harris, Almerigi and Kirsch (2000) asked university undergraduates to imagine holding a young infant in their arms. This investigation was an extension of one of Weiland and Sperber's (1970; see above) experiments with mothers. The researchers found that holding biases were correlated with handedness and sex of the participants. The main results of this study indicate a significant left-hand preference in holding for both right-handed men and right-handed women. However left-side preference for holding was weaker for left-handed women, and absent in left-handed men. Clearly, a left bias when holding an infant is a robust phenomenon that does not require a real stimulus in order to be shown. In addition, these results are consistent with involvement of right hemisphere arousal and leftward direction of attention in the phenomenon; this seems to be more pronounced in females than in males.

\subsubsection{Non-human Primate Studies}

It is interesting to note that the first study on cradling in humans was stimulated by Salk's (1960) observations of a rhesus macaque mother who showed a clear left bias in cradling her infant. The first systematic study with nonhuman primates awaited the publication by Manning and Chamberlain (1990), who investigated left-side cradling in chimpanzees, gorillas and orang-utans. The three species exhibited strong left-side cradling (85\% for chimpanzees, $82 \%$ for gorillas, and for three out of the four orang-utans).

To explain the observed bias in the great apes, Manning and Chamberlain (1990, 1991) and Manning, Heaton and Chamberlain (1994) relied on a hypothesis already proposed for humans (see above) according to which a left-side cradling would make easier the monitoring of emotions and could have a twofold function. Firstly, with a left-side cradling, the mother would be more able to monitor the emotional level of her infant with her left visual field (and maybe with her left hearing field). Such a bias would activate, in a direct way, the right hemisphere, which is reputed to be the most efficient in the processing of emotions. Secondly, with this postural bias, the infant would be better able to interpret the emotional condition of his/her mother while the left hemiface of the mother is presenting to him/her; this is the more expressive side of the face at an emotional level. It is worth mentioning that Hauser (1993) reported in rhesus monkeys an identical asymmetrical pattern for emotional expressions, namely more expressiveness for left side (see Chapter 13 by Weiss et al.). Other studies have revealed differentiated patterns of expressions depending on the nature of the emotions. Thus, marmosets were shown to exhibit right hemisphere specialization for the production of negative emotional expressions and vocalizations, and left hemisphere specialization for the production of social contact communication (HookCostigan and Rogers, 1998). Left carrying (but not cradling) was also found in 41 rhesus macaque mothers (Tomaszycki et al., 1998). However, the presence of left-side cradling or holding biases has not been unequivocally reported in non-human primates. Thus, Tanaka (1989) found no population bias in a group of eight Japanese macaque mothers. In the great apes, Manning, Heaton and Chamberlain (1994) found a left bias in cradling 
among chimpanzees. But such a bias was not observed in a small group of wild chimpanzees (Nishida, 1993), whereas in the same species a slight right bias was reported (Dienske, Hopkins and Reid, 1995) or no bias at all (Hopkins et al., 1993a). Finally, two out of four rehabilitated orang-utan mothers (Rogers and Kaplan, 1996) exhibited a significant right-side preference. Moreover, data collected by these same authors (pers. comm., June 2000) on wild orang-utans have confirmed the right-side bias for carrying the babies.

\subsection{Early Motor Asymmetries}

This section reports published evidence concerning early motor asymmetries in newborns and young infants. As in the preceding section, we start by reporting and summarizing human data and then move to literature on non-human primates.

\subsubsection{Human Studies}

Some motor asymmetries in human neonates need to be mentioned because of their possible relation with handedness. In addition to the available evidence of prenatal behavioural asymmetries (e.g. in thumb-sucking; Hepper, Shahidullah and White, 1991), several studies have demonstrated that human newborns, while supine, predominantly turn the head into a right-sided position (Gesell and Ames, 1947). For example, Coryell and Michel (1978) found that, during the first 3 months, an average of $75 \%$ of the infants $(n=35)$ laid in a supine position maintained a significant right-side head posture (see also Thompson and Smart, 1993; Rönnqvist and Hopkins, 1998). Moreover, this phenomenon is also apparent in preterm infants (Konishi et al., 1987).

Several authors have postulated and found a relation between head-turn bias and later manual preferences. Thus, Coryell and Michel (1978) observed that the asymmetrical head position preference is a reliable elicitor of an asymmetrical tonic neck reflex (ATNR). This ATNR has the consequence of providing the infants with more visual experience of their right hand than of their left hand. Shown by the latter authors, at 12 weeks of age, infants begin to exhibit a difference between their right- and left-hand's response to a visually presented stimulus. In addition, Michel (1981) observed that headturn bias was present until 2 months of age, and that it was a predictor of preferential hand use in pre-reaching tasks at both 16 and 22 weeks. This association between head orientation preference and hand preference was explained by the differential visuomotor experience of the two hands, the right hand receiving more visually guided contacts than the left hand Because of this opportunity to observe their right hand, infants may develop better eye-hand coordination with that hand, thereby giving it an advantage over the left in visually guided reaching' (Michel, 1981, p. 687). A similar relation was obtained in a study by Konishi et al. $(1987): 80 \%(n=82)$ of their supine infants turned their head to the right and more than $88 \%$ of these participants preferentially used their right hand when tested in a reaching task at 9 and 18 months of age.

\subsubsection{Studies with Monkeys and Apes}

Two kinds of asymmetries in non-human primate infants are worth mentioning: one concerns nipple preference, and the other is related to asymmetries in head turning (see the above section reporting data on human infants).

Nipple preference was recorded among a group of 40 Japanese macaque infants by Tanaka (1989). After 1 month of age, all infants used only one of the two nipples during more than $80 \%$ of contact time; however, the choice of nipple was symmetrical at the group level ( 21 preferences for the right and 19 for the left nipple). Some evidence of nipple suckling preference was described by Nishida (1993) among wild chimpanzee mother-infant pairs. The infants displayed preference for the left nipple (as measured by first contact and duration). Moreover, an explicit relation is made by the author between the left nipple preference he observed and cradling by the mother (see also the asymmetries reported in the same species by Manning and Chamberlain, 1990) by stating that 'cradling patterns of neonates by their mothers are likely to be related to the left nipple preference in chimpanzees' (Nishida, 1993, p. 50). Rogers and Kaplan (1998) examined the relation between nipple preference, carrying by the mother and hand preferences in a sample of common marmosets during the first 60 days postpartum. The authors found no relation between nipple preference and hand preference, and no relation between cradling and hand preference. However, their results indicate a significant relation between nipple preference and side of the mother on which the infant was carried (incidentally, it should be noted that this relation disappeared when cradling by the father was included in the analyses). This latter result is thus consistent with Nishida's (1993) findings concerning chimpanzees.

A final study is available on nipple preference in monkeys. Tomaszycki et al. (1998) observed 41 rhesus macaque mother-infant dyads during the first 6 weeks of life. A significant left-side population bias emerged at the group level for nipple preference. This preference was evident during the first 3 
weeks but vanished in the later weeks. Since the authors did not find a lateral bias in maternal cradling (see above), they hypothesized that the cradling bias (when observed) might reflect a bias in the infant's nipple preference rather than a bias in the mother's behaviour. If so, asymmetries in cradling might result from adjustment on the part of the mother to allow the infant to reach its preferred nipple.

Asymmetries in head orientation in infants have also been studied in some monkeys and apes. Thus, Hopkins and Bard (1995) observed a sample of 43 nursery-reared chimpanzees from birth to 3 months of age in both prone and supine positions. While the chimpanzees in the prone position did not exhibit any side bias, 36 of them expressed a consistent bias when in a supine position: 30 oriented toward the right and six toward the left. Recording of head orientation during the first two postnatal weeks was performed in tufted capuchins (Westergaard, Byrne and Suomi, 1998). More specifically, the author noted the length of time for which an infant maintained its head on the right or left side of its mother's back as she carried the infant dorsally. Although 12 infants showed longer durations on the left side and only four on the right, statistical comparisons of the two biases did not reach significance.

\subsection{Comparative Approach of the Methods}

This variability in the results for maternal behaviours could be caused by differences in the methodologies used among authors. Some (e.g. Hopkins et al., 1993a) have focused on newborn chimpanzees, while others (e.g. Manning and Denman, 1994) have observed human infants from birth until 2 years of age. Moreover, some researchers have chosen the position of the head as a measure (e.g. chimpanzees: Manning and Chamberlain, 1990; humans: Manning and Chamberlain, 1991), while others (e.g. macaques: Hopkins et al., 1993a; Tomaszycki et al., 1998) recorded the hand used by the mother to hold her infant when she was seated (cradling) or when she was walking (carrying). It seems likely that this tendency for a left-side cradling is related to the nature of the object that is held or, for humans, the manner in which the experimenter asked the mother to hold the object could have an effect on the laterality of the cradling side. It is thus important to take into consideration the nature of the object (inanimate, lifesize newborn dolls or real newborns) in the interpretation of the data.

As shown in the preceding sections, asymmetrical cradling of their infant by human mothers, in particular during non-feeding interactions, appears to be a robust phenomenon. However, there is still a paucity of detailed natur- alistic work in this area of human (Wind, 1982) and non-human ethology (Saling and Cooke, 1984). For example, most of the human research was carried out under experimental conditions or consisted of surveys of published photographic material.

Furthermore, an important aspect of this left-side cradling has not been examined sufficiently: namely, the role of the infant or its substitute in determining all or part of the observed bias in the mother. Thus, the nature of the object that is held as well as the instruction provided by the experimenter to the participant about to hold the object could have an effect on the laterality of the cradling side. In fact, in some studies (e.g. SouzaGodeli, 1996), human participants did not express the expected bias when they were requested to hold inanimate objects. Moreover, most of the studies refer to cradling behaviour by recording the position of the infant in mother's arms or on the mother's hip (Salk, 1960; Saling and Cooke, 1984). Only some authors also took into consideration the hand (left or right) used by the mother to hold the infant (Saling and Tyson, 1981; Saling and Bonert, 1983).

The presence of a left-side preference for maternal cradling has not always been reported for non-human primates. This variability in the results for maternal behaviours may be due to differences in the methodologies used among authors. Thus, Manning and Chamberlain (1990) did not record manual laterality of the mother, but they considered the position of the head of the infant in relation to the midline of the mother's body. Nevertheless, these authors interpreted their results in terms of cradling side preference. In other words, with the same terminology (i.e. 'cradling'), some researchers have chosen the infant head position as a measure of lateral bias (e.g. Manning and Chamberlain, 1990), while other researchers have recorded the hand (or arm) used by the mother to hold the infant when she was seated (e.g. Tomaszycki et al., 1998; Damerose and Vauclair, 1999). Further, some studies distinguished between maternal cradling and maternal carrying. The latter term usually implied that the mother was walking (e.g. Hopkins et al., 1993b; Tomaszycki et al., 1998). However, Nishida (1993) used the term of cradling, but the behaviour recorded corresponded more to carrying, according to the above definition.

It is thus useful to describe and to compare the different methods and definitions used by the authors in their work. For that purpose, we will distinguish four basic behavioural categories (i.e. holding side, head side, nipple preference and grasping side). 


\subsection{Cradling, Carrying or Holding Patterns}

9.5.1. A symmetries in Human Participants

We first review the evidence concerning patterns of asymmetries for infant cradling, carrying and holding, from the human literature.

\subsubsection{Free Observation}

We report in this paragraph some studies concerned with the different behaviours listed above which did not use any specific sampling technique. Thus, Salk (1960) conducted the first study on the laterality of maternal cradling and for that purpose observed 287 human mothers with their newborn babies. To assess a preference for one side of infant holding by the mother, Salk relied on free observation sessions of the mother-infant human dyads at a hospital. He found (Salk, 1960) that both right- and left-handed mothers had a significant tendency to hold their babies on the left side (see Table 9.2), close to the heart. This effect appeared to be automatic and without awareness on the part of the mother. This original finding opened the way to other investigations in order to find out the factors responsible for this observed bias in cradling. Thus, Salk (1973) hypothesized that a postpartum separation could have an effect on the holding pattern. In order to investigate this hypothesis, Salk selected, as an experimental group, 115 mothers who had experienced prolonged separation (at least $24 \mathrm{~h}$ ) from their infant after birth. In addition, as a control group, 286 mothers were selected at random from mothers attending the clinic who had experienced any prolonged postpartum separation from their infant. During the experimental session, the experimenter took the baby and presented the infant directly to the midline of the mother's body. Next, the experimenter noted on which side the mother held the baby and then asked a series of questions to obtain background data, including handedness of the mother. The control group showed a marked preference for holding the baby on the left side, while the experimental group did not show such a side preference (see Table 9.2).

In order to assess whether the head orientation could influence the side of cradling, Thompson and Smart (1993) unobtrusively observed a total sample of 150 mother-infant pairs during a first test session. Between the first headturning test (see Section 9.6.1, Table 9.4) and grasping tests (see Section 9.8.1, Table 9.7) the mother was asked to pick up her baby from the crib to give it a cuddle. Observations were made of the side on which each mother held her baby and the position she laid her baby back down in the crib after the grasping tests: right or left lateral, supine or prone. Thompson and Smart found a close to significant $(\mathrm{p}=0.074)$ relationship between head-turning classification and maternal holding, with a higher proportion of babies held to the left (Table 9.2) turning their head to the right (see Table 9.4). Here an inverse relation between the side of the cradling and the head orientation of the infant was observed. However, other studies (Bundy, 1979; Saling and Tyson, 1981), which used a doll resembling a lifesize real infant and controlled for the head orientation, did not confirm these findings (see Section 9.5.1.3; Table 9.2).

Most studies bore out Salk's assumption of a left-side tendency in infant holding (Table 9.2). The question of lateral preferences has to be addressed when an object is held instead of a human or a substitute. In a recent study, Hopkins and Parr (unpublished observations) employed a naturalistic observational method with 1505 adult human participants (746 males, 859 females). The experimenters observed individuals while they were carrying either objects or infants in natural social settings. Carrying was here defined as walking upright for at least $5 \mathrm{~s}$, while holding an infant or an object ventrally between the waist and shoulder. Left-sided carrying was defined as the lateral displacement of the object or infant to the left of the participant's midline. Right-sided carrying was similarly defined as a lateral displacement to the right. Objects or infants positioned at the midline were omitted from analysis. The gender of the participant, but not the sex or age of the infant, was recorded. Overall, a significant interaction was found between gender and carrying bias $(\mathrm{X} 2(1,1505)=17.70, \mathrm{p}<0.001)$ with females showing more left-sided carrying than males (Table 9.2), but no significant interaction was found between the lateral bias and the type of item being carried by the participant.

Here carrying an infant or an object produced similar results. However, Weiland and Sperber (1970) did not find a left-side tendency when women held a pillow (see Table 9.2). Nevertheless, in the first part of their study, Weiland and Sperber (1970) observed 48 patients (28 females, 20 males) in an anxiety situation (they were receiving dental therapy). The dentist asked patients to hold a rubber ball firmly against their chest and the observer noted with which hand the ball was held and the side position of the ball on the chest. Participants showed a tendency to hold the ball on the left side, but most of them used the right hand (Table 9.2). In addition, the observed left-side preference for holding was significantly stronger for women than for men ( $\mathrm{p}<0.05$ ). Thus, for the same behaviour, Weiland and Sperber (1970) found opposite results when they recorded the side position of the ball instead of the hand used to hold the ball. These findings reinforce the need to describe clearly and define what behavioural scores the observer is collecting while recording cradling behaviour. 
Table 9.2. Summary of studies on cradling, holding and carrying in humans.

\begin{tabular}{|c|c|c|c|c|c|c|c|c|c|c|c|c|}
\hline Study & Participant & Procedure & Measure & Individual criterion & Condition & $\mathrm{N}$ & Right & Left & No preference & Bias & Statistics & \\
\hline \multicolumn{13}{|l|}{ Free observation } \\
\hline Salk (1960) & $\begin{array}{l}\text { Mother-infant } \\
\text { pair }\end{array}$ & Obs. & $\begin{array}{l}\text { Infant holding } \\
\text { side }\end{array}$ & 1 bout & $\begin{array}{l}\text { Left-hander } \\
\text { Right-hander }\end{array}$ & $\begin{array}{r}32 \\
255\end{array}$ & $\begin{array}{l}21.9 \% \\
16.9 \%\end{array}$ & $\begin{array}{l}78.1 \% \\
83.1 \%\end{array}$ & $\begin{array}{l}0 \% \\
0 \%\end{array}$ & $\begin{array}{l}\mathrm{L} \\
\mathrm{L}\end{array}$ & $?$ & $?$ \\
\hline \multirow[t]{2}{*}{$\begin{array}{l}\text { Weiland and } \\
\text { Sperber (1970) }\end{array}$} & Patient of & $\begin{array}{l}\text { Obs in anxiety } \\
\text { situation }\end{array}$ & $\begin{array}{l}\text { Hand used to } \\
\text { hold ball }\end{array}$ & 1 bout & Female & 28 & 20 & 5 & 3 & $\begin{array}{l}\mathrm{R} \\
\mathrm{R}\end{array}$ & $?$ & 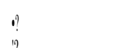 \\
\hline & & & $\begin{array}{l}\text { Ball position } \\
\text { on chest }\end{array}$ & 1 bout & $\begin{array}{l}\text { Female } \\
\text { Male }\end{array}$ & $\begin{array}{l}28 \\
20\end{array}$ & 1 & $\begin{array}{r}19 \\
7\end{array}$ & $\begin{array}{r}8 \\
12\end{array}$ & $\begin{array}{l}\mathrm{L} \\
\mathrm{L}\end{array}$ & $?$ & $?$ \\
\hline \multirow[t]{2}{*}{ Salk (1973) } & \multirow[t]{2}{*}{$\begin{array}{l}\text { Mother-infant } \\
\text { pair }\end{array}$} & \multirow[t]{2}{*}{ Obs. } & \multirow[t]{2}{*}{$\begin{array}{l}\text { Infant holding } \\
\text { side }\end{array}$} & \multirow[t]{2}{*}{ I bout } & Control group & 286 & $23 \%$ & $77 \%$ & $0 \%$ & $\mathrm{~L}$ & $?$ & $?$ \\
\hline & & & & & $\begin{array}{l}\text { Prolonged } \\
\text { separation group }\end{array}$ & 115 & $47 \%$ & $53 \%$ & $0 \%$ & No & $?$ & $?$ \\
\hline $\begin{array}{l}\text { Thompson and } \\
\text { Smart (1993) }\end{array}$ & \multirow{2}{*}{$\begin{array}{l}\text { Mother-infant } \\
\text { pair } \\
\text { Adult female }\end{array}$} & Obs. & $\begin{array}{l}\text { Mother cradling } \\
\text { side }\end{array}$ & I bout & & 132 & 28 & 104 & 0 & $\mathrm{~L}$ & $?$ & $?$ \\
\hline $\begin{array}{l}\text { Hopkins and } \\
\text { Parr (submitted) }\end{array}$ & & Naturalistic obs. & Carrying position & I bout & $\begin{array}{l}\text { Infant } \\
\text { Non-infant }\end{array}$ & $\begin{array}{l}381 \\
378\end{array}$ & $\begin{array}{l}148 \\
126\end{array}$ & \multicolumn{2}{|l|}{$\begin{array}{l}233 \\
252\end{array}$} & $\begin{array}{l}\mathrm{L} \\
\mathrm{L}\end{array}$ & $?$ & $?$ \\
\hline & \multirow[t]{2}{*}{ Adult male } & \multirow[t]{2}{*}{ Naturalistic obs. } & \multirow[t]{2}{*}{ Carrying position } & \multirow[t]{2}{*}{ I bout } & Infant & 371 & 177 & 194 & & $\mathrm{~L}$ & $?$ & $?$ \\
\hline \multirow{11}{*}{$\begin{array}{l}\text { Sequential sampling } \\
\text { Saling and } \\
\text { Cooke (1984) }\end{array}$} & & & & & Non-infant & 375 & 172 & 203 & & $\mathrm{~L}$ & $?$ & $?$ \\
\hline & \multirow{10}{*}{$\begin{array}{l}\text { Mother-infant } \\
\text { pair }\end{array}$} & \multirow[t]{10}{*}{$\begin{array}{l}\text { Sequential } \\
\text { sampling }\end{array}$} & \multirow{2}{*}{$\begin{array}{l}\text { Infant cradling } \\
\text { position in arm } \\
\text { Infant } \\
\text { cradling position } \\
\text { on hip }\end{array}$} & 1 bout & $\begin{array}{l}\text { All the three } \\
\text { groups }\end{array}$ & 134 & 13 & 110 & \multirow[t]{2}{*}{11} & $\mathrm{~L}$ & \multirow[t]{2}{*}{$?$} & \multirow[t]{2}{*}{$?$} \\
\hline & & & & 1 bout & $\begin{array}{l}\text { All the three } \\
\text { groups }\end{array}$ & 16 & 3 & 13 & & $\mathrm{~L}$ & & \\
\hline & & & \multirow[t]{3}{*}{$\begin{array}{l}\text { Infant cradling } \\
\text { position }\end{array}$} & \multirow[t]{3}{*}{ I bout } & Black group & 50 & 4 & 40 & 6 & $\mathrm{~L}$ & $=49.11$ & $\mathrm{P}<0.001$ \\
\hline & & & & & Colored group & 50 & 6 & 41 & 3 & $\mathrm{~L}$ & $\dot{\mathrm{X}}=53.55$ & $\mathrm{p}<0.001$ \\
\hline & & & & & Indian group & 50 & 6 & 42 & 2 & $\mathrm{~L}$ & $x^{2}=58.23$ & $\mathrm{p}<0.001$ \\
\hline & & & \multirow{5}{*}{$\begin{array}{l}\text { Infant transport } \\
\text { position in arm } \\
\text { Infant transport } \\
\text { position on hip } \\
\text { Infant transport } \\
\text { position }\end{array}$} & 1 bout & $\begin{array}{l}\text { All the three } \\
\text { groups }\end{array}$ & 112 & 14 & 81 & \multirow[t]{2}{*}{17} & $\mathrm{~L}$ & $?$ & $?$ \\
\hline & & & & I bout & $\begin{array}{l}\text { All the three } \\
\text { groups }\end{array}$ & 38 & 6 & 32 & & $\mathrm{~L}$ & $?$ & $\bullet$ \\
\hline & & & & 1 bout & Black group & 50 & 3 & 30 & 17 & $\mathrm{~L}$ & $x_{2}=21.88$ & $\mathrm{P}<0.001$ \\
\hline & & & & & Colored group & 50 & 9 & 41 & 0 & $\mathrm{~L}$ & $\dot{X}=55.71$ & $\mathrm{P}<0.001$ \\
\hline & & & & & Indian group & 50 & 8 & 42 & 0 & $\mathrm{~L}$ & $x^{2}=59.67$ & $\mathrm{p}<0.001$ \\
\hline
\end{tabular}

\begin{tabular}{|c|c|c|c|c|c|c|c|c|c|c|c|c|}
\hline \multirow{5}{*}{$\begin{array}{l}\text { Manning and } \\
\text { Chamberlain } \\
\text { (1991) }\end{array}$} & $\begin{array}{l}\text { Mother-infant } \\
\text { pair }\end{array}$ & Sequential test & $\begin{array}{l}\text { Infant cradling } \\
\text { position }\end{array}$ & I bout & Control group & 50 & $38 \%$ & $62 \%$ & $0 \%$ & $\mathrm{~L}$ & $?$ & $?$ \\
\hline & & & & & REO' & 50 & $24 \%$ & $64 \%$ & $12 \%$ & $\mathrm{~L}$ & $?$ & $?$ \\
\hline & & & & & LEO' & 50 & $60 \%$ & $40 \%$ & $0 \%$ & $\mathrm{R}$ & $x^{2}=1.62$ & $\mathrm{p}>0.05$ \\
\hline & & & & & Left-hander & 20 & 10 & 9 & 1 & No & $?$ & $?$ \\
\hline & & & & & Right-hander & 130 & 51 & 74 & 5 & $\mathrm{~L}$ & $?$ & $?$ \\
\hline \multicolumn{13}{|l|}{ Imagined situation } \\
\hline \multirow[t]{2}{*}{$\begin{array}{l}\text { Weiland and } \\
\text { Sperber (1970) }\end{array}$} & Women & $\begin{array}{l}\text { Hold pillow in } \\
\text { anxiety situation }\end{array}$ & $\begin{array}{l}\text { Pillow holding } \\
\text { side }\end{array}$ & 1 bout & Pillow holding & 21 & & & 20 & No & & \\
\hline & & $\begin{array}{l}\text { Imagine real } \\
\text { infant in anxiety } \\
\text { situation }\end{array}$ & $\begin{array}{l}\text { Pillow holding } \\
\text { side }\end{array}$ & 1 bout & Pillow as infant & 21 & & 10 & 10 & & 10 shifts No $\rightarrow L$ & \\
\hline \multirow[t]{3}{*}{ Bundy (1979) } & $\begin{array}{l}\text { Student male } \\
\text { and female }\end{array}$ & $\begin{array}{l}\text { Imagine real } \\
\text { infant situation }\end{array}$ & $\begin{array}{l}\text { Infant baby } \\
\text { doll position }\end{array}$ & 1 bout & $\begin{array}{l}\text { Doll's head in } \\
\text { midline }\end{array}$ & 47 & & $78 \%$ & & $\mathrm{~L}$ & $?$ & $?$ \\
\hline & & & & & $\begin{array}{l}\text { Doll's head } \\
\text { on the left }\end{array}$ & 47 & & $68 \%$ & & $\mathrm{~L}$ & $?$ & \\
\hline & & & & & $\begin{array}{l}\text { Doll's head on } \\
\text { the right }\end{array}$ & 47 & & $85 \%$ & & $\mathrm{~L}$ & $?$ & $?$ \\
\hline \multirow[t]{4}{*}{$\begin{array}{l}\text { Saling and } \\
\text { Tyson (1981) }\end{array}$} & $\begin{array}{l}\text { Nulliparous } \\
\text { female }\end{array}$ & $\begin{array}{l}\text { Imagine real } \\
\text { infant situation }\end{array}$ & $\begin{array}{l}\text { Arm used to } \\
\text { hold the doll }\end{array}$ & I bout & $\begin{array}{l}\text { All the three } \\
\text { groups }\end{array}$ & 120 & 13 & 107 & 0 & $\mathrm{~L}$ & $\times 2=73.63$ & $\mathrm{P}<0.001$ \\
\hline & & & & & $\begin{array}{l}\text { Doll's head in } \\
\text { midline }\end{array}$ & 40 & 7 & 33 & 0 & $\mathrm{~L}$ & $\times 2=32.4$ & $\mathrm{p}<0.001$ \\
\hline & & & & & $\begin{array}{l}\text { Doll's head on } \\
\text { the left }\end{array}$ & 40 & 4 & 36 & 0 & $\mathrm{~L}$ & $X 2=25.6$ & $\mathrm{p}<0.001$ \\
\hline & & & & & $\begin{array}{l}\text { Doll's head on } \\
\text { the right }\end{array}$ & 40 & 2 & 38 & 0 & $\mathrm{~L}$ & $\mathrm{X}^{2}=16.9$ & $\mathrm{P}<0.001$ \\
\hline $\begin{array}{l}\text { Saling and Bonert } \\
\text { (1983) }\end{array}$ & Preschooler girl & $\begin{array}{l}\text { Imagine real } \\
\text { infant situation }\end{array}$ & $\begin{array}{l}\text { Arm used to } \\
\text { hold the doll }\end{array}$ & 1 bout & & 53 & 18 & 35 & 0 & $\mathrm{~L}$ & $x_{2}=5.45$ & $\mathrm{P}<0.02$ \\
\hline Bogren (1984) & Couple with & Imagine real & Child position & Position shown & Female & 81 & $20 \%$ & $80 \%$ & $0 \%$ & $\mathrm{~L}$ & $?$ & 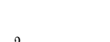 \\
\hline & & & & & & & & & & & & \\
\hline \multirow{4}{*}{$\begin{array}{l}\text { Manning and } \\
\text { Chamberlain } \\
\text { (1991) }\end{array}$} & Girls & $\begin{array}{l}\text { Imagine real } \\
\text { infant situation }\end{array}$ & $\begin{array}{l}\text { Infant baby } \\
\text { doll position }\end{array}$ & I bout & Control group & 95 & $20 \%$ & $80 \%$ & $0 \%$ & $\mathrm{~L}$ & $?$ & $?$ \\
\hline & & & & & REO' & 98 & $21 \%$ & $79 \%$ & $0 \%$ & $\mathrm{~L}$ & $?$ & $?$ \\
\hline & & & & & LEO' & 99 & $38 \%$ & $61 \%$ & $1 \%$ & $\mathrm{~L}$ & $\times 2=4.5$ & $\mathrm{p}<0.05$ \\
\hline & & & & & BEO' & 96 & $33 \%$ & $66 \%$ & $1 \%$ & $\mathrm{~L}$ & $\times 2=9.4$ & $\mathrm{p}<0.05$ \\
\hline
\end{tabular}


'able 9.2. (cont.)

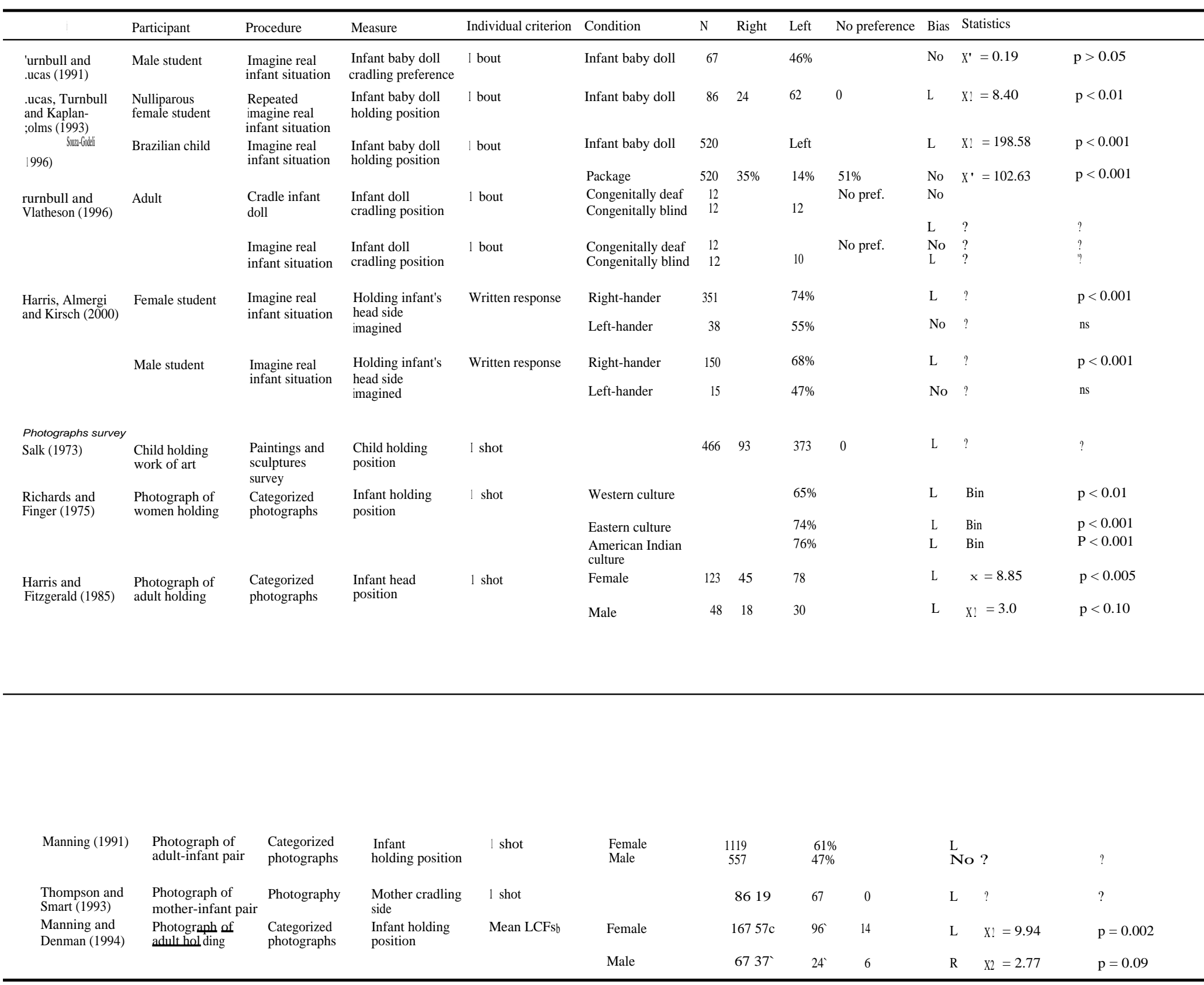

Obs, observation; N, number of participants; L, left bias; R, right bias; No, no preference; ?, information not provided in the original paper; ns, non-significant. See details in text: 'REO, right eye occluded; LEO, left eye occluded; BEO, both eye occluded. bLCFs = left cradling frequencies. 'Right, LCF of 0-49\%; Left, LCF of 51$100 \%$; No, $50 \%$.

The abbreviation 'Bin' refers to a binomial test. 
In a second part of the study by Hopkins and Parr (unpublished observations), these authors also assessed handedness, carrying an infant, as well as different kinds of objects, and footedness as well as participant's variables including age, gender and parity, with a 26-item questionnaire. Participants were 761 human adults ( 380 males, 381 females). The qualitative response to the 22 laterality questions (five-point scale) were coded numerically and each response was assigned a weighted value $(-2$ to +2$)$ corresponding to the participants response (always left to always right). A Pearson product moment correlation revealed a significant association between each of the four laterality indices. A significant proportion of variance was accounted for in this analysis $(\mathrm{R}=0.57, \mathrm{~F}(6,719)=56.68, \mathrm{p}<0.001)$. Handedness, followed by footedness, age and sex, all significantly predicted laterality in carrying biases.

It is worth reporting that Jenni and Jenni (1976) showed sex differences in carrying books by recording the spontaneous book-carrying methods of 2256 students from kindergarten to old age (distinguishing ten levels). In carrying methods used by females, arms and books partially covered the front of the body, while those used by males employed 'open' positions, with the body unobstructed. Jenni and Jenni divided positions into two basic types. In type I, one or both arms wrapped around the books, whilst the forearm, on the outside of the books, supported them. In type II, one arm and hand at the side of the body supported books. A single record of each individual's carrying method was made: no significant difference in carrying between males and females $(\mathrm{p}>0.50)$ was found up to grade 1 . Both displayed a pattern equivalent to the college males and usually used some variant of the type II. From grade 2, significant differences emerged between the sexes: females were more likely to use type I, and males more likely to use type II carrying.

\section{Sequential Sampling}

Saling and Cooke (1984) used 50 human mother-infant pairs in each of the population groups (black, coloured and Indian) to investigate any cultural effects on the holding pattern. Women were observed whilst in the waiting room of clinics for healthy babies. A sequential sampling procedure was used. Holding positions were coded in terms of the placement of the infant against the mother's body (i.e., infant held in one arm, supported on one hip, or held against the ventral surface of the mother's body in a midline position) and the laterality of the holding position (right, left or midline) was measured. After each observation, the mother was questioned about her own age and that of her infant. For descriptive purposes, the holding positions observed were referred to as cradling behaviour. The majority of women in each group cradled their infants in a lateralized fashion, and only $7.33 \%$ of mothers exhibited a midline cradling position. Of the two lateralized cradling positions (arm and hip), the arm position (88.5\%) was the more frequently used in each group. The distribution of the cradling position was significantly biased towards the left side in the three cultural groups. There was no evidence of cross-cultural variation in the direction and degree of lateral bias $(\mathrm{X} 2(4)=2.89, \mathrm{p}>0.50)$, with the infant being cradled in the arm and on the hip more often on the left side (Table 9.2).

With another group in a second part of their study, Saling and Cooke (1984) used 50 human mother-infant pairs in each of the three population groups (black, coloured and Indian). Mothers were observed while carrying their infants towards the clinic. A dorsal midline position was included in coding the holding position. The second part was procedurally similar to the first one. For descriptive purposes, the holding positions observed were referred to as transport behaviour. The majority of women in each group transported their infants in a lateralized fashion and only $11.33 \%$ of mothers exhibited a midline transport position. The arm position (71.4\%) was preferred to the hip position. A majority of infants were on the left side (see Table 9.2).

Using the same sampling procedure, Manning and Chamberlain (1991) assessed the importance of the visual field used during cradling. They assigned 150 mothers with their infants (ranging in age from 12 days to 11 months) to one of three groups: control, left eye occluded (LEO), and right eye occluded (REO). The mother was asked to walk and place her infant on a cot and return to her seat. She was then requested to walk to the end of the cot, pick up the infant and return (carrying the infant) to the seat, and sit down. The position of cradling (i.e. left, midline or right) was noted when the mother had completed the task. The hand that the mother normally used for writing was recorded. The control and REO groups exhibited a tendency to hold on the left side, which was absent in LEO (Table 9.2). Manning and Chamberlain (1991) also noticed an effect of infant age, namely that left-side cradling decreased with increasing infant age, and suggested that their findings revealed some evidence of an association between cradling tendency and handedness. Of the 150 participants, 20 reported a predominant use of the left hand for writing (Table 9.2). However, the differences between the leftand right-handed participants were not significant $\left(X_{2}^{2}=0.97, p>0.05\right)$.

2.5.1.3. Imagined Situation

Several studies have examined the effect on cradling a doll of instructions to imagine that it was real or had some other status. In a vast majority of those studies, participants were required to imagine that the doll was a real baby 
and had to hold it. Thus, to examine the possibility that the mother's preference for holding infants on the left side was based upon the normal asymmetry of the infant's head orientation, Bundy (1979) divided 141 students into three groups (15 males, 32 females in each group). Participants were then required to hold a lifelike infant doll as if it was a real baby. The head position of the doll was midline, or turned to the left or the right side. Handedness and prior experience with infants were evaluated by questionnaire. Between $68 \%$ and $85 \%$ of participants held the doll on the left side, irrespective of the head orientation of the doll (Table 9.2). The more experience mothers had had with infants, the stronger was the leftward holding bias. Males (73\%) had an equivalent left holding tendency to females (79\%). Subjects with little experience of infants were more influenced by the doll's head orientation.

In a study that examined whether experience of infants affected cradling bias (Bundy's hypothesis; Bundy, 1979), Turnbull and Lucas (1991) observed 67 male students (all non-fathers). Cradling preferences were established with a lifesize neonatal doll, and participants also completed a handedness and infant experience questionnaire. No significant leftward cradling was found for male participants (Table 9.2). Moreover, cradling preference was not related to handedness. No relation appeared between direction of cradling and the participant's experience of or attitude towards infants (obtained by the questionnaire). Saling and Tyson (1981) tested 120 nulliparous female students. Participants were required to cradle a lifelike doll in the preferred arm. The head position of the doll was rotated either to the left or the right of its body midline, or fixed in the midline position. Each condition contained 40 participants. Saling and Tyson (1981) found that the majority of participants (i.e., 89\%) spontaneously cradled the doll in the left arm (Table 9.2). These findings were close to those obtained by Bundy (1979).

These different studies seem to show that the head position of the doll does not disrupt the leftward preference in cradling position, contrary to the assumptions made by Thompson and Smart (1993).

Also using an imagined situation, Saling and Bonert (1983) examined cradling behaviour and its relation to handedness in 53 pre-school girls. The experimenter stood opposite to the girl, presented a doll (lifelike infant size) and then asked the girl to hold it so that it could fall asleep. Handedness was established via the use of ten familiar unimanual actions. In this condition, the leftward cradling bias (Table 9.2) appeared to be independent of total handedness score. With the same aim, the psychiatrist, Bogren (1984), conducted semistructured interviews in 81 parents. All women and men were interviewed during the 13th to 14th week of the mother's pregnancy, and again during the week following delivery. During the first interview, questions were asked about social and psychological background, and feelings during pregnancy. During the second interview, participants were questioned about pregnancy and parturition. The women and men were asked to imagine that they were holding their infant, and then to show how they did it. All subjects were asked if they used the right or left hand when writing. Women and men showed a tendency to hold their infant to the left (see Table 9.2) and their lateral preference was independent of their handedness.

Several explanations have been provided to explain the leftward tendency for cradling. Thus, in order to investigate Manning and Chamberlain's (1990) suggestion that a relationship exists between the right hemisphere specialization for emotional processing and leftward cradling (see above), Lucas, Turnbull and Kaplan-Solms (1993) tested 86 nulliparous female students. They divided the testing procedure into three stages. In the first stage, they assessed all participants for their preferred cradling bias using a lifesize doll. Each participant was requested to stand in front of a centrally placed doll and was asked to imagine that the doll was a real baby, and to pick up and rock it to sleep. This procedure was then repeated to ensure that the direction of cradling first chosen was stable for that participant. In the second stage, the authors used a tachistoscopic test to measure perception of facial emotion (Campbell, 1978). The final stage involved an assessment of facial expression (asymmetry of smile, Bennett et al., 1987): 16 leftward and 16 rightward cradling participants were randomly recruited from the total group and individually photographed when smiling. Findings revealed a significant leftward side for holding position of an infant baby doll, as if it were a real infant, in an imagined situation (Table 9.2). However, no significant difference between cradling groups was noticed for perception or expression of facial emotions. Thus, perception and expression of facial affect appeared to be independent.

Nevertheless, Manning and Chamberlain (1991) reported that the visual field could have an important effect (see Section 9.2.1. Lc). They assigned 388 girls to four groups: control, LEO, REO, and both eyes occluded (BEO). Each participant was asked to hold the doll as if it were a small baby. The position of the cradling (i.e. left, midline or right) was recorded. Girls in the REO group held the doll on the left side in the same proportion as displayed by controls; however, LEO and BEO groups differed from controls (Table 9.2). All participants were asked which hand they usually used for writing. No association between handedness and lateral cradling preferences was found.

To investigate whether the role of auditory information could also be as critical as the visual information (Sieratzki and Woll, 1996), Turnbull and 
Matheson (1996) hypothesized that the left-cradling bias should be reduced in deaf mothers. For that purpose, 12 congenitally deaf people and 12 congenitally blind individuals were requested to cradle a lifesize infant doll, or to imagine cradling an infant. No clear lateral cradling bias was found for deaf people. In contrast, blind individuals displayed a left-side preference, both in the 'doll condition' and in the 'imaginary condition' (Table 9.2). However, the size of the sample was too small to establish the importance of auditory information.

In a second part of the study by Weiland and Sperber (1970), 21 adult women were asked to hold a pillow against them. Then, the same participants were offered the pillow a second time after being placed in an anxietyoriented situation. The participants were asked to hold the pillow as if it were a real baby and to comfort it. A significant number of individuals that first held the pillow in the midline shifted the pillow to the left. In the anxiety-oriented situation (Table 9.2), females as well as males tended to hold a ball on the left side of the chest. In contrast, using a naturalistic condition, Hopkins and Parr (submitted) failed to find any difference in carrying between a real infant and a non-infant object (see above and Table 9.2)

Furthermore, Souza-Godeli (1996) investigated what were the side preferences for cradling a doll and for holding a package of the same size and weight. The participants were 520 Brazilian children. The doll as well as the package were presented (on different trials, in a randomized sequence) in the vertical position at the midline of the child's body. The observer recorded each child's behaviour. Souza-Godeli (1996) reported a left-sided preference for holding the doll but not for the package (Table 9.2). In order to assess whether the reaching-hand preference in an emergency situation was a good indicator of the mothers' handedness, Hatta and Koike (1991) monitored the hand used by 43 adult humans (28 right-handers, 10 left-handers and 5 ambidextrous participants) to take up an object. Handedness was scored. Participants were required to take up an important object as fast as possible in an experimentally simulated emergency situation. Participants were first informed that the object they were to take up and bring back was a very important material. Two experimenters recorded the hand used to take up the object. A total of 12 trials were conducted for each participant. No results are given concerning the asymmetry of the manner of taking up a baby, but the correlation coefficient between hand used and handedness was 0.898 .

Harris, Almerigi and Kirsch (2000) proposed a completely imagined simulation study where 554 university undergraduates were used as participants: 501 right-handers (150 males, 351 females) and 53 left-handers (15 males, 38 females). Participants, with closed eyes, were asked to imagine holding a young infant in their arms; they were later asked to write on which side (left or right) they were holding the infant's head. In addition, they were requested to complete a short questionnaire in order to rate: their experience with young babies; their comfort level while imagining themselves holding the infant; their sex and age; and, finally, their handedness on a five-point scale. Right-handed women and men exhibited significant left-side holding biases that did not appear for left-handed subjects (Table 9.2).

\subsubsection{Surveys of Photographs}

Salk (1973) collected paintings and sculptures involving an infant or a child being held by an adult. Of 466 such works of art that were examined in art museums and galleries, $80 \%$ depicted the young being held on the left side and $20 \%$ on the right side (Table 9.2). Thompson and Smart (1993) photographed live mothers when they were holding their infants and also found a left-side preference (Table 9.2). In an attempt to assess the validity and universality of Salk's (1960) contentions, Richards and Finger (1975) analysed 268 photographs of men and women from Western (100), Eastern (112) and American Indian (56) cultures. A significant trend for women to hold children on the left side of the body was also observed in each culture. Men, however, did not show such a preference. Each photograph was categorized by the sex of the adult holding the child, whether the child was positioned on the left or the right side, and whether the child was nursing. However, the authors presented their results in a figure that did not allow one to know exactly the distribution of individuals in each condition. Nonetheless, findings indicated that women in all three cultural divisions were more inclined to hold their children on their left side than on the right (Table 9.2).

In the assessment of whether a similar left-side cradling preference might occur in men as well as in women, Manning (1991) sampled 1696 'family album' photographs (1119 females, 577 males). The pictures were then categorized with respect to sex and age of the children, the sex of the adult, the kinship relationship of the adult with the child, and whether the child was positioned to the left or right side. Findings demonstrated a highly significant difference between women and men $\left(\mathrm{X}_{2}=27.7, \mathrm{p}<0.001\right)$. Earlier, Harris and Fitzgerald (1985) investigated lateral holding preferences, in the same conditions, with a sample of 216 photographs of adults (52 males, 164 females) holding infants. Women showed a significant left-side preference for holding infants in non-feeding and feeding situations (63\%). Men also $(65 \%)$ exhibited a significant left-side preference in holding behaviour (Table 9.2). The breast-feeding exhibited a leftward bias (56\%), but was not signifi- 
cant compared to the non-feeding (63\%) and the bottle-feeding $(75 \%)$ conditions.

Manning and Denman (1994) also classified 3297 photographs in which infants were cradled on one side (left or right) of adults (2361 females, 936 males). From this sample, the authors identified 167 women and 67 men, represented by at least six photographs. Photographs were categorized by whether the child was positioned to the left or right side. Photographs for which the infant was in a midline position or being fed were excluded. For holding, women showed a left-side bias (mean 60.1\%, Table 9.2) and men a right side (mean $54.1 \%$, Table 9.2); this difference between the means of men and women was found to be significant $(\mathrm{t}(231)=3.57, \mathrm{p}=0.0004)$.

In brief, for the three categories of cradling, holding and carrying, the majority of the studies confirmed the original findings of Salk (1960; Table 9.2) that about $80 \%$ of individuals cradled, held or carried infants or children on the left side.

\subsubsection{Asymmetries in Non-human Primates}

We now examine the relevant literature pertaining to the existence of cradling, carrying and holding behaviours in non-human primate species. As in the preceding section, we have categorized the available studies by considering the different methods used to assess these lateral biases.

9.5.2.1. Free Observation

While observing the behaviour of a mother rhesus monkey and her newborn, Salk (1960) noticed for the first time that the mother had a marked tendency to hold the newborn on her left side, frequently with the newborn's ear pressed against her heart. In an attempt to systematize this observation, Salk described the behaviour of one mother rhesus monkey and of her newborn, and in particular the side of cradling. Salk (1960) observed that the newborn was held on the left side 40 times and on the right side only twice (Table 9.3).

Hatta and Koike (1991) investigated monkeys' hand preference in an emergency situation, caused either by an alarming voice or a moving mirror that frightened all the individuals in the cage. The subjects were 8 monkey mother-infant dyads (3 Japanese macaques, 4 Taiwan monkeys, 1 Bonnet monkey). The experimenter checked the hand with which the mother took her baby up when she was in the experimentally provoked emergency situation. Recording was conducted between 17 and 32 times with an inter-trial interval of 40 min over 3 days. Of the 8 mothers, 7 significantly used their left-hand more frequently than the right-hand (Table 9.3). No mother showed a right-hand preference in this experimentally induced emergency situation.

R95.2.2. Continuous Recording

Nishida (1993) investigated the effect of maternal cradling on nipple preference; for that purpose, hand support of five mother-infant dyad chimpanzees was recorded continuously when the mother was supporting the infant with one hand while walking and carrying it. Unfortunately, it is not clear how the data were analysed. Except for one pair, involving a male infant cradled more with the mother's left hand (43 bouts with the left hand and 15 with the right hand), the number of bouts was too small to reach any conclusion about ${ }_{i}$ ndividual biases in the other four mother-infant pairs (Table 9.3).

Dienske, Hopkins and Reid (1995) observed each of nine chimpanzee mother-infant pairs for $1 \mathrm{~h}$ a day, and recorded whether or not the mother had her hand or arm around the infant (i.e. holding). No left bias was found in these ape groups (Table 9.3).

Some studies, however, showed a leftward tendency in cradling or carrying patterns. Thus, Hopkins et al. (1993b) videotaped 11 bonobos (five males and six females) during their morning feeding for approximately 2 days each week. Seven behavioural units were observed and scored for laterality. Among these behaviours, the carrying was coded according to whether an animal used one or both hands to grasp an object, an infant, or a food item and physically carried it to a different location in the cage, with at least three strides. For all measures, the unit of analysis was a bout rather than a single act. The mean percentage of right-hand use for carrying was $42.7 \%$, which indicated a significant left-side bias (Table 9.3). The effect of quadrupedal and bipedal postures on lateral bias in carrying was also analysed. For eight subjects, data were available in both postural conditions. The bipedal condition had the effect of increasing the use of the left hand in the carrying measure. Hopkins and De Waal (1995) studied ten additional bonobos (five males and five females). Videotaped observation periods were $60 \mathrm{~min}$ in duration. Binomial z-scores and the percentages of right-hand use were also calculated in the same condition as in Hopkins et al. (1993b). Hopkins and De Waal (1995) found a significant deviation from 50\% right-hand use, with a mean percentage right usage of $38 \%$ for carrying. When the data of Hopkins et al. (1993b) were combined with those of Hopkins and De Waal (1995) in order to establish the presence or absence of asymmetries at a population level for each of the behavioural measures, carrying patterns were significantly biased towards the left hand (Table 9.3). A similar finding 
Table 9.3. Summary of studies on cradling, holding and carrying in non-human primates

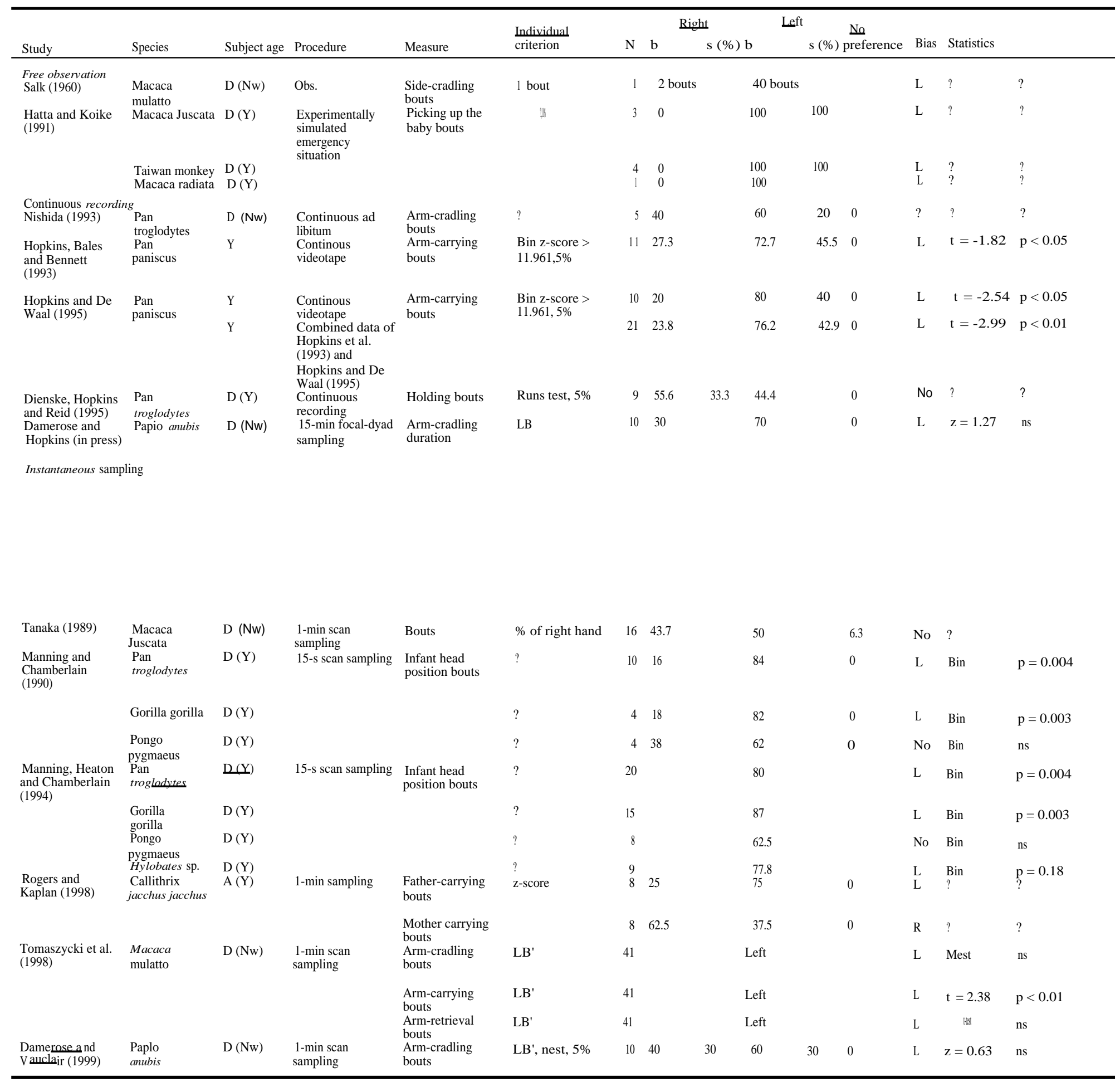

Obs., observation; D, mother-infant dyad; A, adult; Nw, newborn; Y, young; N, number of subjects; b, number (or percentage) of biased subjects; s, percentage of significant biased subjects; L, left bias; R, right bias; No, no preference; ?, information not provided in the original paper; ns, non-significant. See details in text: aLB (lateral bias), (\#R - \#L) / (\#R + \#L). Bin refers to a binomial test.

All results are given by reporting percentages of the side preference. A percentage was calculated whenever possible from the available data. 
is provided by Damerose and Hopkins (2001) who recorded continuously ten mother-infant dyads of baboons: a tendency for the left arm to be used by mothers to cradle the infant was found (Table 93).

\section{S9.5.3.3. Instantaneous Sampling}

The studies described in this section investigated whether left-side cradling is widespread in apes. First, Manning and Chamberlain (1990) published preliminary observations on 18 captive apes. Each primate mother-infant pair was observed for at least $1 \mathrm{~h}$ and observation sessions were uninterrupted whenever possible. Cradling behaviour was defined as ventral holding of the infant when the infant's head was touching the mother's torso. A scan and instantaneous sampling with an interval of $15 \mathrm{~s}$ was used to record the infant's head position. The infant's head was recorded as being on the mother's left side, on the right side or in the midline. The position of the infant's head was the only variable recorded. For example, suppose the infant's head to be on the left and the torso and limbs to the right of the mother's midline; this would then be recorded as a left-side position. Observations of suckling periods were excluded from the analyses. Fourteen animals exhibited an appreciable excess of left-side cradling (Table 9.3). Only one animal, an orang-utan mother, showed a marked preference for cradling her infant on the right side (92\%). Considering the overall average lateralization $(\mathrm{N}=18)$, a significant $(\mathrm{X} 2=11.5, \mathrm{df}=1$, $\mathrm{p}<0.005)$ lateral bias appeared towards the left side $(79 \%)$ versus the right side $(21 \%)$. In each species, an average of $80 \%$ mothers cradled on the left side.

In a new study, Manning, Heaton and Chamberlain (1994) presented data on a sample of 52 mother-infant pairs of captive apes. The total sample of captive mother-infant ape pairs was 20 chimpanzees, 15 gorillas, 8 orangutans and 9 gibbons. For this study the authors used the same method adopted by Manning and Chamberlain (1990; see above). Chimpanzees, gorillas and gibbons showed a left-side cradling bias that did not appear in orang-utans (Table 9.3).

Several works using a scan and instantaneous sampling are available in investigations with monkeys. For example, Rogers and Kaplan (1998) scored behaviour in eight common marmoset infants by direct observation for half an hour with 1-min interval sampling, four times daily and for the first 60 days of life. Carrying was recorded separately for mother, father and siblings, and concerned four locations on the body: in front or on the back (middle positions), on the left and on the right. Scores for carrying did not include suckling. Hand preferences during the first 2 months after birth were also recorded in a range of situations, including holding an object, holding food and touching others. Results show that mothers carried their infants more often than fathers $(53.3 \%$ and $44.7 \%$, respectively) with a left bias for fathers and a right bias for mothers (Table 9.3). Tanaka (1989), also using an instantaneous sampling with a 1-min sample interval, recorded the hand used by the mother to embrace her newborn in 40 mother-infant Japanese macaque dyads. This study failed to find a significant bias (Table 9.3).

Tomaszycki et al. (1998) followed longitudinally 41 rhesus macaque mother-infant dyads ( 25 females, 16 males) living in social groups. Their goal was to assess whether rhesus monkeys show evidence of a left-side cradling bias. They measured the relative contribution of mother and infant to lateral cradling, as well as the effect of several maternal and infant characteristics on lateral cradling. Observation sessions began on either the first or second day of the infant's life and continued until the infant reached 6 weeks of age. Scan and instantaneous sampling procedures with 60-s intervals were used in data collection for lateral biases in nipple preferences (see Section 9.7.2.) and maternal cradling. An ad libitum sampling procedure was also used throughout the observation sessions to record infant carrying and retrieval. The observer coded the hand used to perform maternal cradling, infant carrying and retrieval. Mothers exhibited a significant left-arm bias for carrying their infant, but no population bias for maternal cradling or retrieval were observed. However, the cradling bias became more left-sided with increasing maternal experience (Table 9.3). Using the same procedure, Damerose and Vauclair (1999) also found a significant left-side cradling preference in ten baboon mother-infant dyads (Table 9.3).

In short, asymmetry patterns concerning cradling, holding and carrying of the infant by the mother are not as obvious for monkeys as they are for apes. All together, most of the studies with monkeys and apes showed either a left side or no preference for cradling as well as for carrying. This pattern of biases is remarkably similar to the pattern we have described for humans in the preceding section.

\subsection{Head Orientation and Position}

We examine in this section a number of studies concerned with asymmetries in head orientation and head position of newborns, both human and nonhuman, as these patterns might be related to postural asymmetries of the mother. 


\subsubsection{A symmetries in Human Participants}

9.6.1.1. Free Observation

Thompson and Smart (1993) conducted an observational study with a total sample of 150 mother-infant pairs. The direction of 35 baby's lateral head movement at birth was recorded as the first observable lateral movement. It was noted whether the baby rotated to its right or left or not at all: a score of right, left or zero was given for each baby. Most babies turned their head significantly more to the right than to the left (Table 9.4).

\section{Experimental Studies}

The studies described below recorded the head-turning response in human infants, following head rotation of the infant by the experimenter.

Michel and Goodwin (1979) tested 109 newborn infants (50 females and 59 males). They set three criteria for a participant's inclusion in the study: (1) a full-term vaginal delivery birth; (2) a birth record; and (3) the attending obstetrician must have filled out the researcher's forms indicating the position of the infant's head during descent. These forms also gave the experimenters permission to visit the mother to obtain her agreement for observing her baby. The infant's birth position was determined by occiput position relative to the mother at four phases during delivery. The newborn's posture was observed during $16-50 \mathrm{~h}$ postpartum. The infant was placed in a supine position, the head was held gently in midline position for $1 \mathrm{~min}$. Then, the head was released and state, head and digit positions were recorded on a checklist every $6 \mathrm{~s}$ for $1 \mathrm{~min}$. After this observation, the head was held gently with the left ear flat on the mattress for $1 \mathrm{~min}$. Again, postures and state were recorded every $6 \mathrm{~s}$ for the following minute. Finally, the head was held in the same way to the right. The order of starting head orientations (midline, left, right) was counterbalanced between infants.

Immediately following these procedures, the infant was held in a prone position, and the whole set of procedures was repeated. The infant's head was placed in midline and turned to the left and then also turned to the right. Head orientation while supine was recorded in three categories: head-right turn, defined as nose/chin to right of right nipple with right ear touching the mattress; head-left turn, defined similarly for left nipple; midline position, defined as nose/chin position between right and left nipples. Head orientation while prone was recorded as: head-right, occiput oriented over or beyond left scapula; head-left, occiput oriented over or beyond right scapula; midline position, occiput between scapulae. Head orientation data were analysed separately for the supine and prone conditions. Significantly more infants oriented right and had significant head-right preferences while supine (Table 9.4). There were no significant differences while prone (Table 9.4).

Later, using the same procedure, the direction of supine head orientation was determined by Michel (1981) for 150 normal full-term neonates (81 males and 69 females), by two separate assessments during the 16-48 $\mathrm{h}$ after birth. Each assessment consisted of three 2-min trials. The distribution of preferences was biased significantly to the right (Table 9.4), and sex differences were not significant.

Konishi, Mikawa and Suzuki (1986) selected 44 infants (25 males and 19 females) from 82 relatively low-risk preterm infants: all were born before the 37 th week of pregnancy. An additional sample of 53 healthy, mature infants were used as controls. The infant was placed in the supine position and the experimenter held the head, at the temple, between thumb and forefingers until no resistance was felt. The head was then released and the direction of the first head turn was recorded. This test was repeated five times. Infants turning their heads toward the same side four times or more were considered to have asymmetrical head-turning preferences; those turning their heads to one side three times or less were regarded as having bilateral head-turning preferences. Hand preference was examined at the age of nine and 18 months and was defined in terms of reaching. The infant sat on the mother's lap and the experimenter placed a toy directly in front of the infant at chest level for $60 \mathrm{~s}$. Preference in using the right or left hand was established when an infant reached for the toy with the same hand three times or more. Until the age of 6 months, more than half of the preterm infants turned their heads to the right side preferentially, while most full-term infants turned their heads bilaterally at 3 months (Table 9.4). At 9 months, a significant $(p<0.02)$ number of preterm and full-term infants who had preferred to turn their heads to the right at 1 month, used their right hand more than their left. Similarly, most of the preterm and full-term infants with head preference to the left used their left hand more often than their right at 9 months.

With a total sample of 150 mother-infant pairs, Thompson and Smart (1993) recorded lateral head turning when the infant was supine. Neonatal head turning behaviour was tested on two consecutive days following birth. The baby was laid in a central, supine position with its head held in the midline for $15 \mathrm{~s}$, then released. The baby's first lateral head turn, after release, in excess of $20^{\circ}$ was recorded. After a period of 1 min the baby's head was returned to the midline. The baby was tested for five trials with intertrial intervals of $1 \mathrm{~min}$ and then a further five trials were given a day later. Of the 144 infants tested for head-turning preference, 96 showed a predominant lateral head-turning bias, but no sex differences were found (Table 9.4). 
Rdnngvist and Hopkins (1998) carried out a study on head orientation using an apparatus with 18 newborn infants (10 females and 8 males). The supine newborn was secured on a custom-built platform by a belt covering the trunk. The head was placed in a holder that, when unlocked, allowed the head to move from side to side through a range of $140^{\circ}$. A standard protractor mounted on the head end of the platform together with a pointer attached to the holder's axis were used to measure the number of degrees that the head turned from the midline position. At the start of a trial, the head holder was locked in the midline position. It was unlocked once the infant's head was judged to be in the body midline with the eyes centered. This procedure was repeated three times. For each trial, the movement of the head, as indicated by the pointer traversing the protractor in $5^{\circ}$ units, was scored second by second from the video recordings up to a maximum of $20 \mathrm{~s}$. After the third repetition, the maintenance of a head position was recorded for $5 \mathrm{~min}$. The mean number of turns to the right was 2.0, compared to 0.94 for left-sided and only 0.1 for the midline position. The percentage of time involving a right-sided position $(M=60.6 \%)$ was significantly greater than for left-sided position $(M=27.9 \%)$, and midline $(M=11.4 \%)$. There was a significant difference between the two positions, $t(17)=2.1, p<0.05$, such that the angle to the right $\left(M=35.4^{\circ}\right)$ was larger than to the left $\left(M=27.3^{\circ}\right)$. In short, the majority of infants turned maximally more to the right than to the left for both assumption and maintenance (Table 9.4). The difference between boys and girls was not significant for either assumption or maintenance. In a study using the same procedure as that described by Rdnngvist and Hopkins (1998), Rônnqvist et al. (1998) sampled 15 newborn infants (10 females and 5 males) and found a similar pattern (Table 9.4): namely, the mean number of turns to the right was 2.0 compared to 0.93 for those to the left.

To summarize, most of the human studies reported a right-side bias for head turning of the infant while it was supine, but not when it was in prone (e.g. Michel, 1981). This rightward tendency seems to develop with the age of the infant (Konishi, Mikawa and Suzuki, 1986).

9.6.2. A symmetries in Non-human Primates

9.6.2.1. Free Observation

All studies of head orientation or position in non-human primates (Table 9.5) were conducted with different observational sampling procedures. Thus, Hopkins and Bard (1995) observed the behaviour of 43 chimpanzees (18 


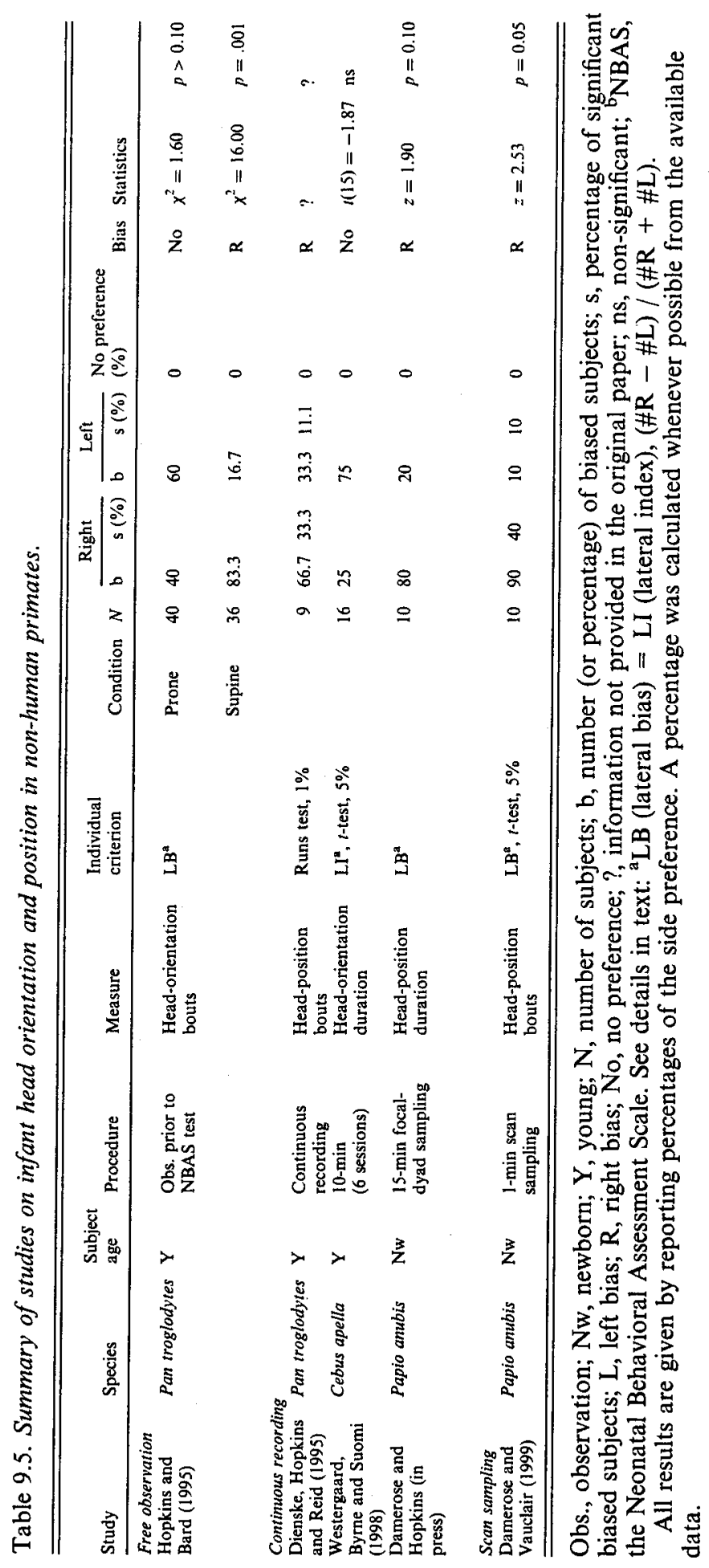

females and 25 males) for the first 3 months of life. Head orientation data were collected prior to the administration of the NBAS test (the Neonatal Behavioral Assessment Scale; Brazelton, 1984) by recording which side of the chimpanzee's face was resting on the sleeping mat. If the chimpanzees were lying prone, then a left-face contact was scored as a right-orientation bias, and a right-face contact was scored as a left-orientation bias. In the event that the chimpanzees were supine (sleeping on their back), a right-face contact was scored as a right-orientation bias, whereas a left-face contact was scored as a left-side bias. At the end of the 3-month observation period, the total frequency of observations for right- or left-sided biases that were crossclassified with prone or supine posture was determined for each subject. An overall significant right-side lateral bias was found for head orientation in the supine posture while not in the prone posture (Table 9.5). A trend toward greater right-side bias in females compared with males was observed but failed to reach statistical significance.

These data suggest that asymmetries in head orientation are present early in life in chimpanzees, and that they may be correlated with functional asymmetries observed in adulthood. For both sleeping postures, no significant sex differences were found in the direction of lateral bias; however, in the supine posture, right-side biases in head orientation were higher in females (93\%) compared to males (76\%). The average LB (that is, right occurrences minus left occurrences divided by right plus left occurrences) score of subjects sleeping in supine posture $(M=0.34)$ was significantly $(\mathrm{t}(37)=-4.45$, $\mathrm{p}<0.01$ ) shifted to the right side in contrast to the average LB scores of subjects in a prone posture $(M=-0.05)$ which was not different from zero $(\mathrm{t}(41)=-9.07, \mathrm{p}>0.10)$.

\subsubsection{Continuous Recording}

Dienske, Hopkins and Reid (1995) observed nine mother-infant pairs of chimpanzees for $1 \mathrm{~h}$ a day. All types of contacts between the infant and the mother's ventral trunk were recorded as on-mother (see above). A distinction was made between head positions being left, midline and right on the mother's chest. Of the 69 testable observation periods, on-mother was eight times significantly left-sided and 21 times significantly right-sided. However, more subjects had a right-side head position than left (Table 9.5). Also, with another small sample of olive baboons (ten infants), Damerose and Hopkins (2001) using a focal-dyad sampling with continuous recording found a rightward head position (Table 9.5).

By contrast, in another study, Westergaard, Byrne and Suomi (1998) collected data from videotape recordings during six 10-min sessions in 16 
mother-reared, tufted capuchin infants (I1 males and 5 females) housed in social groups. These authors adapted a measure of head orientation for humans and chimpanzees (humans: Michel, 1981; apes: Hopkins and Bard, 1995) for use in monkeys that carry the infants dorsally. The observers noted the duration for which an infant maintained its head on the right or the left side of its mother's back as she carried the full weight of the infant (dorsal riding). Most of the subjects were left-side turned (Table 9.5), and no significant differences appeared between males and females.

\subsubsection{Instantaneous Sampling}

Damerose and Vauclair (1999) followed the behaviours of ten mother-infant dyad baboons using a scan and instantaneous sampling procedure. They found a significant right-side head position, with significant individual biases toward the left or the right (Table 9.5).

In brief, similarly to human studies, non-human primate investigations reported most often a right turn for the head of the infant, with the exception of two studies that revealed no preference (in prone posture: Hopkins and Bard, 1995; Westergaard et al., 1998).

\subsection{Nipple Preference}

Preferences expressed by infants may have an important effect on the postural behaviour of the mother (i.e. cradling). We believe it useful to examine the published data in relation to this behaviour in non-human primates (to our knowledge, no data on this possible bias in humans are available).

\subsubsection{Continuous Recording}

Tanaka (1989) used focal-animal sampling with continuous recording on 40 mother-infant Japanese macaque dyads. The point when the infant's mouth touched and left its mother's nipple, and which of the two nipples the infant used, right or left, were recorded. The infant mostly used only one nipple, an average of $90.9 \%$ of nipple contact time. After 1 month of age, all the infants used only one of the two nipples during more than $80 \%$ of nipple contact time. The same tendency, albeit weak, was also detected in the first month, but it did not appear to be biased at the population level (Table 9.6). In another study, Dienske et al. (1995) recorded nine chimpanzee mother-infant pairs, but failed to find any left or right bias (Table 9.6).

On an ad libitum basis, Nishida (1993) observed 34 mother-infant chimpanzee dyads with a focal-animal sampling procedure implying continuous

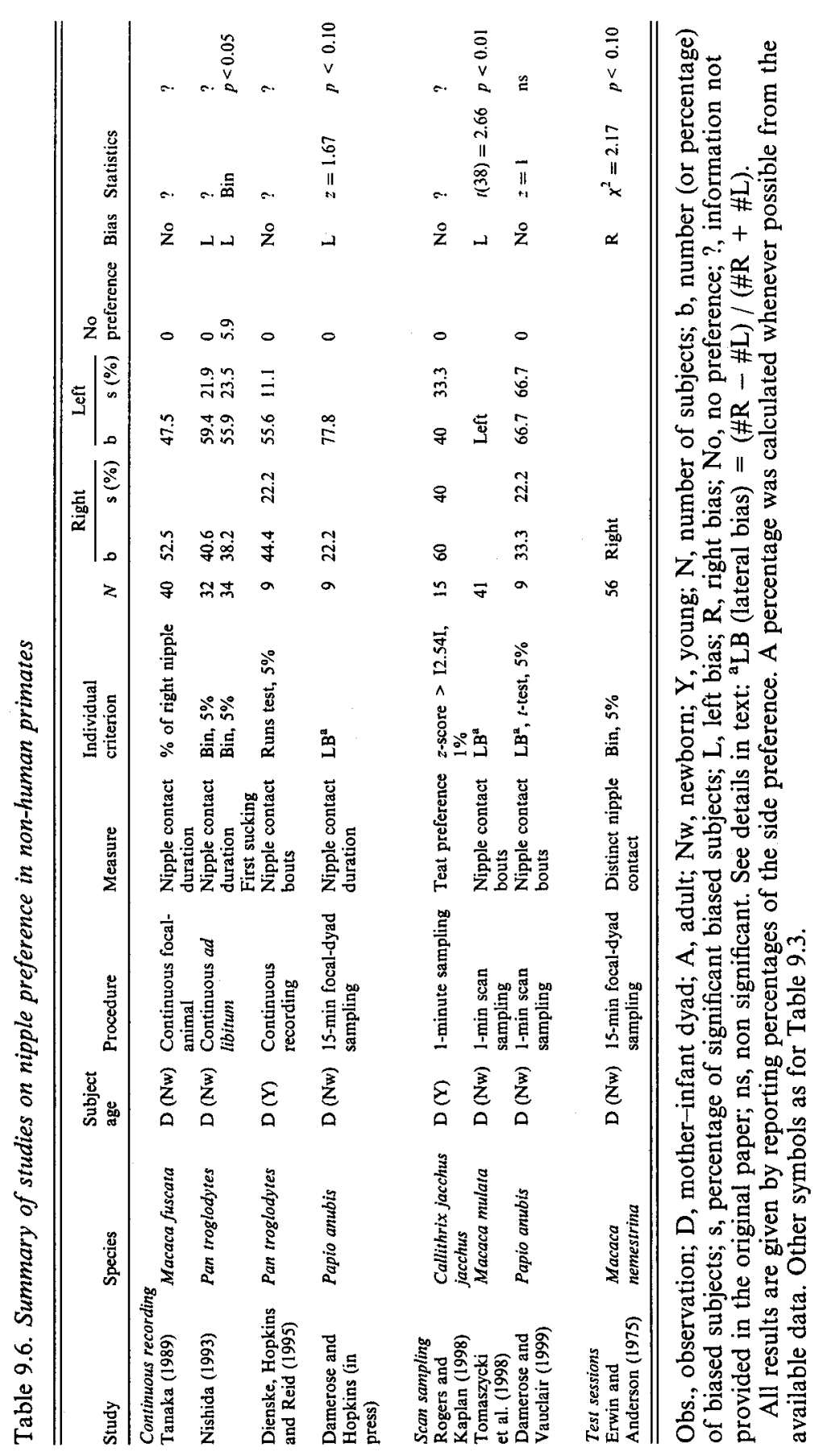


recording. A suckling bout was defined as a period with nipple contact during which no interruption to nipple contact lasted for more than $1 \mathrm{~min}$. Nipple contact renewed after interruptions longer than $1 \mathrm{~min}$ was considered to constitute the start of a new bout. Only nipple contacts lasting more than $10 \mathrm{~s}$ continuously, were treated as a suckling bout, since brief contacts appeared to be 'reassurance nipple contacts'. The number of occurrences of such bouts was 736. Nipple preferences were determined in terms of the nipple sucked first and by measuring the duration of suckling. All of the infants who showed a statistically significant laterality were biased to the left, for both first nipple and contact duration of nipple (Table 9.6). It was likely that the left nipple preference was facilitated by the mothers' tendency to support neonates with their left arm. Damerose and Hopkins (2001) found also a leftward bias in baboons (Table 9.6).

Tanaka (1997) undertook a study with 150 mother-infant dyads in freeranging Japanese macaques (primiparous and multiparous). The aim of the study was to examine how parity-related physiological differences in lactation affect suckling behaviour with an estimate of milk secretion rates. For that purpose, Tanaka used a focal-animal sampling method for motherinfant dyads to record when the infant began to suck its mother's nipple and when it stopped, and computed the duration of a nutritive sucking bout. The findings showed that the infants of primiparous mothers used the preferred nipple less during nutritive sucking than did the infants of multiparous mothers. In nutritive sucking, Japanese macaque infants preferred one single nipple. The infant of primiparous mothers appeared to supplement the physiological drawbacks in their mothers by behavioural means (i.e. by use of the supplementary nipple).

\subsubsection{Instantaneous Sampling}

Rogers and Kaplan (1998) scored the behaviour of a total of 15 common marmosets infants obtained from three different parents. Behaviour was scored daily by direct observation for half an hour of interval sampling every minute. Scoring took into account the side on which each infant suckled, how often it attached to the teat and which infant suckled. The results reveal that the infants had teat preferences with a significant right or left bias at the individual level, and that twins preferred opposite teats. However, teat preferences were not an artifact of twins suckling together, that is, due to only one infant having a preference and thus imposing a preference on the other infant. Their correlation was also not due to counting suckling simultaneously as carrying. 'Carrying' was scored as a non-suckling activity. Comparing infants raised by their father and mother with all infants, ${ }^{i}$ ncluding those raised with their father as well as those raised without their father but in the presence of siblings, the authors found a weak but significant correlation between suckling and carrying. According to them, these findings suggest the possibility that the presence of the father had an influence on the side of infant suckling and carrying by the mother. The scores for hand preferences in the first 2-month period of testing showed no significant biases (i.e. hand preferences had not developed). Also, in the first 2 months of life, there was no significant relationship between hand preference and teat preference ( $r=0.03, \mathrm{p}=0.9$, Spearman correlation). Hand preferences for holding food developed later in all offspring and stabilized by 10-12 months of age. No significant relationship was found between teat preference and hand preference at any age. Among the 15 individuals tested, six infants exhibited a right hand preference and nine had a left-hand preference.

Following the procedure described in Section 9.5.2.3, Tomaszycki et al. (1998) collected data on lateral biases concerning nipple preferences among 41 rhesus macaque mother-infant dyads. Infants showed a significant leftside nipple preference (Table 9.6) in the first weeks of life, and this decreased and became not significant at 3 weeks. Damerose and Vauclair (1999) in nine baboon mother-infant dyads also found, in the same conditions, a trend toward left-side nipple preference (Table 9.6; see also Damerose and Hopkins, 2001).

\subsubsection{Experimental Studies}

The nursing behaviour of 56 (27 males and 29 females) singleton infant pigtail monkeys (Macaca nemestrina) was monitored by Erwin and Anderson (1975). Each infant was observed on two occasions for as long as was necessary to observe ten distinct nipple contacts. Thus, each session was composed of ten two-choice trials. Observers scored each nipple contact only after a period of non-contact had intervened after a previous nipple contact. To allow assessment of the consistency of the phenomenon, a second observation session was conducted on a different day. Infants over 1 month of age showed strong preferences for one of their mother's nipples, while few infants less than 1 month old did so. A trend toward lateral preference (for right nipple) was identical for male and female infants (Table 9.6). Of the 56 infants observed, $46(82 \%)$ showed significant preferences for one nipple over the other. Twenty-four infants exhibited exclusive contact with the preferred nipple. The intersession reliability was remarkably high, 0.94. More 
subjects preferred the right to the left nipple, and no sex differences were found.

In summary, a tendency for a left preference for the nipple suckled seems to emerge from the preceding studies, although a few of them reported opposite biases (see Table 9.6).

\subsection{Grasping}

Asymmetry in the grasping reflex may allow prediction of the future handedness of the infant. It is, however, important to observe that grasping is not a behaviour that involves mother and infant, but is to be considered a motor act similar to reaching. We decided to include this behaviour in our review because spontaneous reaching preferences might affect later hand preferences both in human and in non-human primates.

\subsubsection{Human Studies}

For studying the asymmetry in grasping (Table 9.7), authors have used experimental paradigms to determine which hand first grasps a small rattle (Caplan and Kinsbourne, 1976) or asymmetry in grasping duration (Caplan and Kinsbourne, 1976; Thompson and Smart, 1993). Thus, Caplan and Kinsbourne (1976) tested 21 infants ( 2 months of age), none of whom had a familial left-hander, and five babies who had familial left-handers. In this study, each participant was placed in a sitting position, leaning against the knees of the reclining examiner. At the beginning of each trial, the participant's trunk, limbs and head were centered. There were two parts in the experiment. In the first part, a small rattle was placed in one of the baby's hands and the number of seconds before it was dropped was recorded. Eight trials were run, alternating hands. In the second part, two identical rattles were used, and one was placed in each hand simultaneously. The first hand to drop the rattle and the duration for which the grasp persisted were noted; total of four trials were run. Infants displayed a significant right-hand grasping when one rattle was presented, but no bias when two rattles were simultaneously presented in each hand (Table 9.7); no sex differences emerged for the five familial left-handed participants.

Thompson and Smart (1993) carried out a study with a total of 150 newborn infants. In addition to measuring the infant's head-turning biases (see Section 9.6.1.2), and the maternal cradling-side (see Section 9.5.1), the authors tested the palmar grasp reflex while the baby was sitting centrally on its mother's lap. A rod was placed alternately in the open palm of the

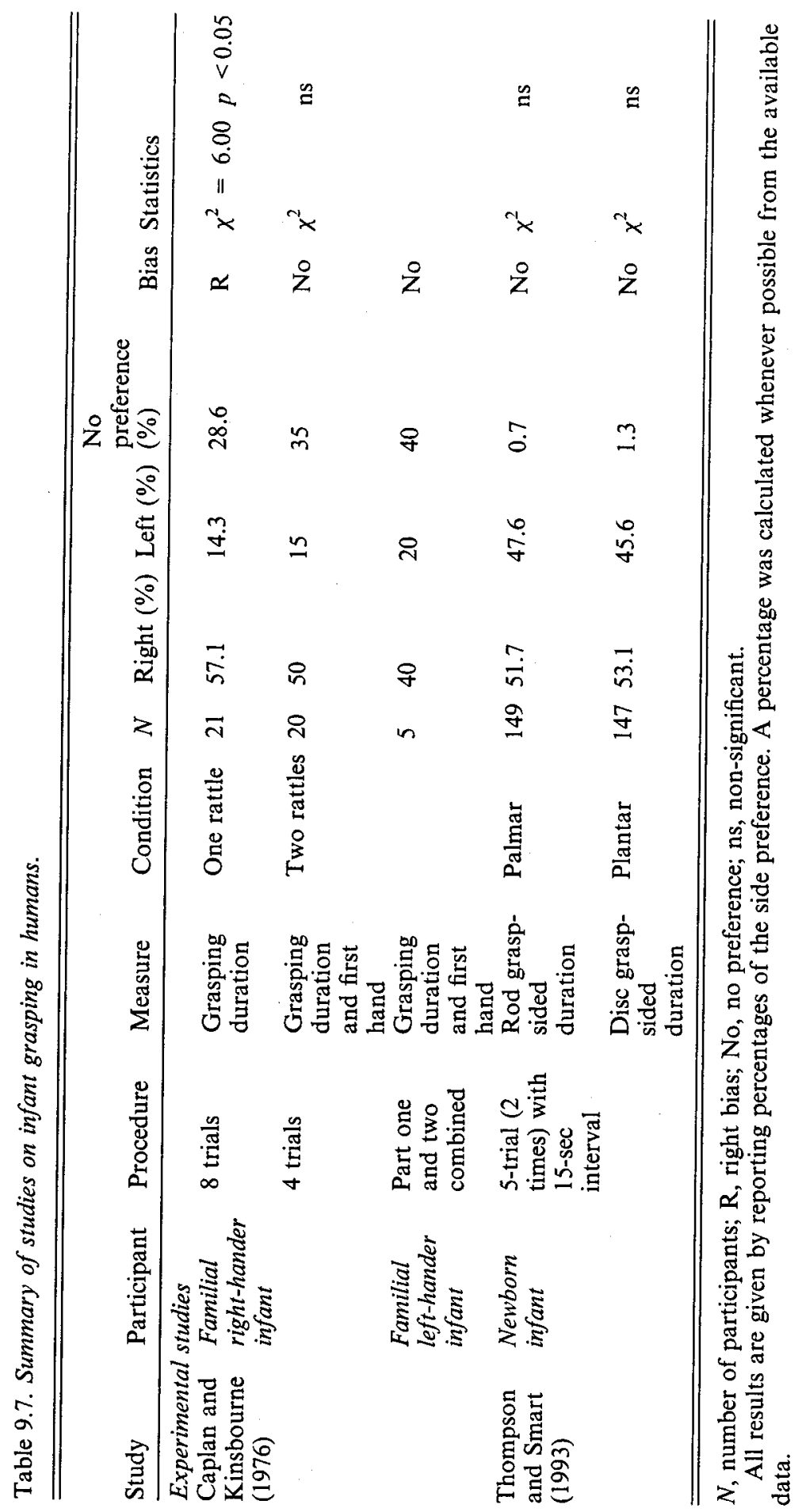


baby's right and left hands. The palmar grasp was defined as occurring when all four fingers closed around the rod and terminated when the rod was released from the grasp of all four fingers. The plantar grasp response was elicited by placing a plastic disc alternately under the baby's right or left toes. The plantar grasp was defined as all four smaller toes gripping the disc and terminated when all four toes extended. The duration of grasp was timed, and two periods of five trials were performed. Ten such trials were given each day, with a 15-s intertrial interval. No significant lateral differences were found in palmar or plantar grasp (Table 9.7). As many babies held for the same duration with their right hand as with the left, and the same held for the plantar grasp response.

\subsubsection{Non-human Primate Studies}

Studies involving non-human primates (Table 9.8) most often utilized experimental test sessions, just as for human studies, with the exception of Westergaard, Byrne and Suomi (1998), who used observations to determine grasp side bouts in 16 tufted capuchin infants (11 males and 5 females). After the head orientation was recorded (see Section 9.6.2.2), the frequency with which an infant used its right or left hand to grasp and manipulate objects, during the time that the infant was not in contact with its mother, was noted. The observer recorded only the initial grasp of an object during each succession of grasping actions in order to maintain independence between data points (McGrew and Marchant, 1997). At 23-24 weeks, subjects showed a significant grasping to the left that disappeared at 47-48 weeks (Table 9.8), and no significant differences were found between males and females.

Other studies used test sessions to determine grasping asymmetries. Thus, Bard et al. (1990) administered the NBAS every other day from 2 days after birth to 6 weeks after birth and then once a week through 12 weeks of life in 12 (7 males and 5 females) chimpanzees. The NBAS is a test designed for neonatal humans that investigates the neurobehavioural integrity and consists of 28 behavioural items and 18 reflexes. Among these behavioural items, we will consider in particular the defensive grasps and for the reflexes, the plantar (foot) grasp, the hand grasp and the tonic neck reflex (TNR; an asymmetric reflex elicited by turning the head to the side when supine). No clear bias was revealed (Table 9.8) in this study.

To explore whether or not newborn chimpanzees exhibit an asymmetry in grasping similar to that observed in human infants, Fagot and Bard (1995) used as subjects 13 neonate chimpanzees. Grasping bouts were recorded using an apparatus made of a gripometer equipped with a strain gauge.

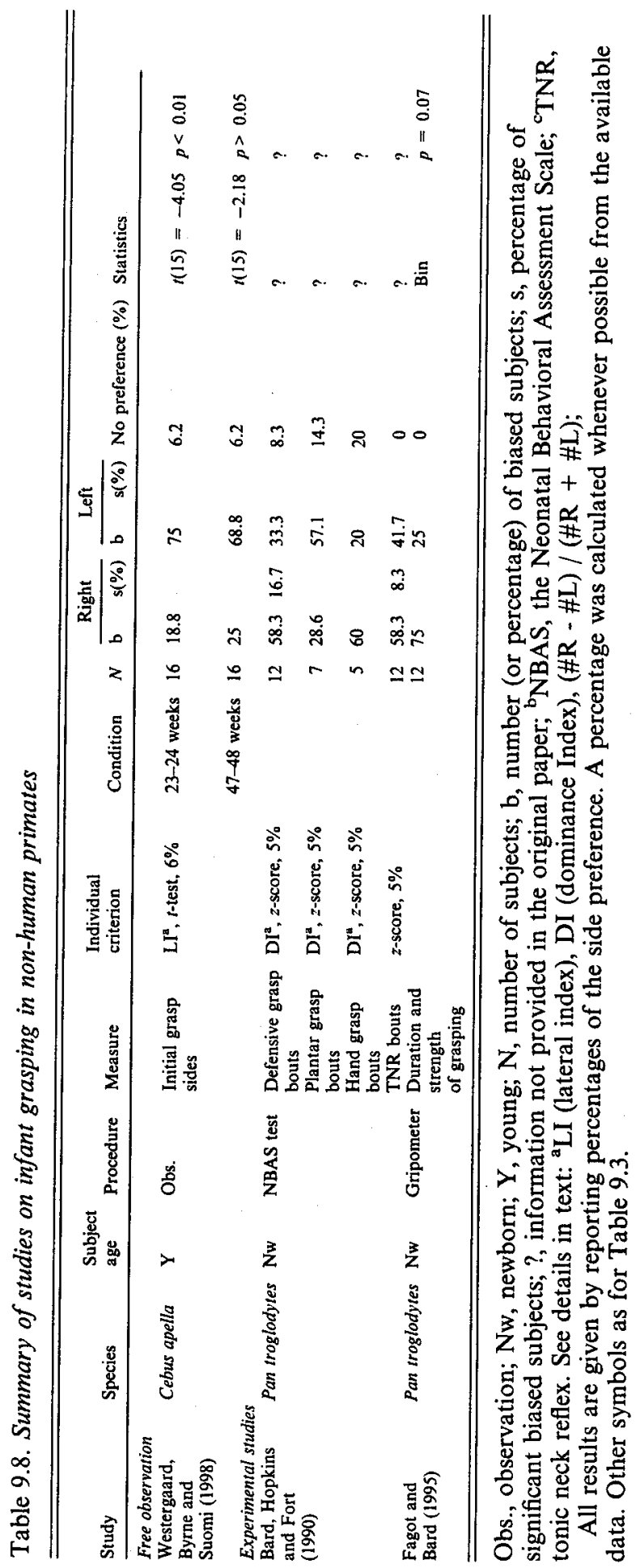


The gripometer consisted of a Lexan stick longitudinally split along twothirds of its length. Grasping applied forces to the strain gauge fixed at the end opposite to the split. During test sessions, data were sampled at $15 \mathrm{~Hz}$. Grasping responses of the hand and foot were recorded. Tests were carried out at least twice a week. The chimpanzee was placed supine on a blanket on the floor. The experimenter recorded one grasping response per hand and foot, following a pseudo-random predetermined order. Grasps were recorded only if the chimpanzees were: (1) in a symmetrical posture; (2) awake but quiet; and (3) not sucking thumb or hand. For both duration and strength, right-hand (and right-foot) responses were longer and stronger than left-hand (and left-foot), respectively, but, except for the strength of the hand, these differences were not significant (Table 9.8).

All together, these studies, which are more numerous for non-human primates than for humans, reveal a wide variability in the asymmetric patterns of grasping.

9.9. A Methodological Proposal to Study the Relationships between Cradling and Other Motor Biases

The above survey of the different methods used to study maternal behaviours shows how important it is to describe clearly and define the procedures, as well as the behavioural units of interest. In fact, we have shown that the bias, for example, for infant holding, can be different depending on the unit of analysis chosen. Thus, Manning and Chamberlain (1990) recorded only the head position of the infant and concluded that there is a cradling bias, whereas Hopkins et al. (1993a) recorded the arm used by the mother to measure infant cradling. We suggest that researchers systematically verify the relation between the units selected before providing any firm conclusion. It is also necessary to specify clearly the sampling procedures used as well as the kind of data analysis performed. In several human studies, there is even an absence of statistical analyses.

Before proposing our descriptions and definitions of measures of lateral biases as we use them in the investigations of laterality in olive baboons, we discuss briefly the advantage of having a non-human primate model to study these questions. The evaluation of human handedness depends on the cultural background and on the criteria used to determine the preferred hand (Porac and Coren, 1981). Moreover, from birth, the world of objects (both social and inanimate) influences humans in an asymmetrical manner and this action expresses itself in a prominent way in maternal behaviour. Provins (1997) assumes that cultural biases in human populations tend to favour the use of the right hand. As a result, individuals who begin in infancy by using their right hand in some unimanual tasks would have this tendency strengthened. The more common the functional neuromuscular activity, the more i will facilitate the acquisition or learning of other motor skills. An example is provided by the mastery of the manipulative action pattern involved in holding a crayon or a paintbrush with the finger of one particular hand.

During the first year of life, the human infant is placed in an oriented environment. As the development of the manual asymmetry in humans starts very early in life (perhaps even during the prenatal period; see Hepper, Shahidullah and White, 1991), the most likely source of influence would come from acts and attitudes of the parents and the teachers. Thus, the study of the effect of maternal behaviour on infants' hand laterality in humans is made difficult by the fact that we are not able to distinguish exactly this environmental contribution from the cultural ones.

Compared to humans, we can assume that non-human primates do not have the same kind of cultural pressures. Firstly, this situation allows us to remove a factor that is hard to determine and to control. The investigation of the development of handedness in non-human primates, in particular in monkeys, should permit us to isolate the effect of maternal behaviour on these biases. Secondly, unlike apes, monkeys and notably cercopithecids, such as baboons, do not have a long breast-feeding period. The young baboon is usually independent from the mother after 5-6 months of age (Altmann, 1980), whereas in chimpanzees the infant can stay with the mother until 4-5 years of age (Lawick-Goodall, 1968). This long breast-feeding period in chimpanzees can induce overlap of two offspring, which in turn might influence infant behaviour and thus affect the postural biases expressed by the mother. Conducting such a study with baboons should prevent overlaps between siblings and thus control better for the influence of maternal behaviour.

\subsubsection{Procedure}

We shall now report the techniques we used for studying lateral biases of behavioural units that involve the mothers' as well as the infants' preferences and postures, in an ongoing study with olive baboons (Papio anubis). The main objective of our study is the effects of postures and hand preferences of the mother on her infant's manual laterality. For that purpose, our investigations involve both observations and experiments. We rely on observations of (1) the asymmetrical nursing behaviours of the mother as well as the postural behaviours of the infant in relation to the mother, and (2) the exploratory 
activities of infants (e.g. carrying of food and non-food items). Moreover, we have devised a set of tasks (both unimanual and bimanual) in order to investigate manual preferences of the mother. It is also planned that, when the infants reach 6 months of age, their manual preferences will be evaluated with the same sets of tasks used for the mothers.

The subjects are $\mathbf{4 3}$ mother olive baboons (Papio anubis) belonging to the colony $(n=90$ baboons) housed in two large outdoor compounds $(20 \mathrm{~m} \times 25 \mathrm{~m})$ at the field station of the Station de Primatologie of the CNRS (Rousset-sur-Arc, France). The group is composed of 2 adult males, 43 adult females, subadults, juveniles and infants. The adults are wild-born and their ages are not known. A tunnel connects the two outside enclosures. Each outdoor compound has an attached indoor building $7 \mathrm{~m} \times 6 \mathrm{~m}$. The baboons can move freely between the indoor and outdoor enclosures, except during the observation periods when they are locked in the outdoor enclosure. The study includes all the pregnant females and their respective infants over a 24 -month period. A small experimental enclosure ( $3 \mathrm{~m} \times 2 \mathrm{~m}$ ) connected to one of the outdoor compounds permits temporary isolation of one or more individual(s) from the rest of the group so that the different tests of hand preference can be carried out. All animals involved in the study are identified by a collar.

\section{Nursing Behavioural Units}

Nursing is evaluated through five basic measures in mother-infant dyads, from birth to 6 weeks of age. Behavioural observation sessions of motherinfant dyads begin on either the first or second day after delivery, and continue until the infant is 6 weeks old. Throughout the first 6 weeks, all mother-infant dyads are observed twice a week using two sampling procedures: (1) scan sampling, in 1-h observation sessions; and (2) focal-dyad sampling, in 15-min observation sessions. The five basic measures of lateral bias that are recorded from either the mother or the infant are maternal cradling, maternal carrying, infant retrieval, infant head position and infant nipple preference. Cradling behaviour is recorded when the mother holds the newborn with one hand (left- or right-cradling arm) or with both hands (both cradling).

This use of cradling is congruent with that proposed by Tomaszycki et al. (1998). Cradling is only recorded when the mother is seated and when she holds the infant ventrally. During the breast-feeding periods, a nipple pre ference is recorded whenever the infant is suckling the left or right nipple. No distinctions are made between the different suckling phases (Tanaka, 1997; feeding or non-feeding period). Thus, all nipple contacts of the infant are counted as suckling. The infant head position is assessed in relation to the midline of the body of the mother (Manning and Chamberlain, 1990). Nonetheless, it could happen that the infant has the head on the right while the mother cradles it with the left arm. We have consequently defined this behaviour clearly. If more than a half of the infant's head is in contact on one side of the mother's torso, we consider it to be a lateralized behaviour (i.e. left or right head position). However, if it is difficult or impossible to determine this lateral bias, then we record it as a 'middle head position'. Infant retrieval occurs when the infant is apart from the mother and the mother reaches to retrieve the infant for any reason. The hand used to retrieve the infant is recorded as left, right or both. Finally, when the mother is walking with the infant held ventrally with one arm (left or right carrying), an event of maternal carrying is defined. Frequently, during maternal carrying, the infant is held with one hand and the balance of the mother when she is walking in a tripedal position is kept with the other hand. When the mother walks without holding the infant, this behaviour is coded as 'no carrying'. In order to complete this ethogram, we include a 'no behaviour' category (i.e. 'no cradling', 'no nipple', 'no head'). This 'no category' is used when behaviours do not correspond precisely to these above defined behavioural units.

Likewise, when it is difficult to specify these behaviours or when they are not clearly visible (e.g. the mother is huddled under other baboons), the behaviour is coded as 'non-visible'.

$$
\text { 9.9.1.2. Scan and Instantaneous Sampling }
$$

The mother-infant dyad is sampled using a scan and instantaneous sampling with an observation session lasting $1 \mathrm{~h}$, with recording at 60-s intervals (Altmann, 1974; Martin and Bateson, 1993). Consequently, a total of 60 scans are obtained for each observation session. A check sheet is used, and, at each scan, the behavioural measures of lateral biases described above are recorded. The observer scans the compound, and changes of behaviour in the mother-infant dyad target at each scan interval are noted, together with a note of whether the infant is suckling or not. Thus, according to the number of dyad targets observed during this 1-h observation session, the observer notes at each interval (the duration of which in seconds $=60$ /number of observed dyads) the behaviour of a new dyad. For that purpose, a stopwatch with a timer, adjustable to the time of $1 \mathrm{~s}$ and with an automatic zero-replay, is utilized. When the same behaviour continues during several 60-s intervals, each scan is considered as a separate instance. 


\subsubsection{5-min Focal-Dyad Sampling}

Conjointly, in the same mother-infant dyads, another observational technique is used, namely the 15-min focal-dyad sampling with continuous recording (Altmann, 1974; Martin and Bateson, 1993). The same behavioural measures of lateral biases (see above, Section 9.9.1.2) are also recorded. For this method, a portable computer (with specific software written in QuickBasic that we have developed) is used in order to record, in the same session, the mothers' and infants' behaviours. By contrast to the scan and instantaneous samplings, this method focuses exclusively on one motherinfant dyad, which allows the observer to follow it with a continuous recording (Lehner, 1996; Damerose and Hopkins, 2001). As our goal is to study the laterality of behaviours, and not their occurrences, we have decided to begin an observation session only if any two of the three main behaviours are present (i.e. maternal cradling, infant head in contact with the mother's torso, nipple contact). If this criterion is not met, the session is delayed by one day for this specific dyad.

\subsubsection{Hand Preference}

Individuals are tested in an experimental enclosure. Pieces of corn and sunflower seeds are used as food items. Preference data are recorded on an audiotape. A trial is recorded only when the baboon is seated at one foodreaching apparatus (screen with a small food box) facing the food box in the midsagittal plane, so that the recorded reach corresponds to a real choice between the hands. A handedness index (HI; see Hopkins, 2001) is calculated with the total number (a minimum of 100 grasps per subject) of right and left reaching, using the same formula as the lateral bias (see Section 9.9.2.1).

To determine the hand preference of each subject, a different apparatus is used, and it provides information concerning the hand used in a one-choice hand situation. Furthermore, other tasks require the baboon to perform a cooperation as well as a coordination of both hands. For example, we use a vertical sliding panel (see Fagot and Vauclair, 1988a, 1988b), a haptic discrimination task (Lacreuse, Fagot and Vauclair, 1992), a sloping plane and a tube task developed by Hopkins (1995).

\subsubsection{Exploratory Behaviours of the Infant}

A focal-dyad sampling method is used to record different categories of exploratory behaviour expressed by the infant (e.g. carrying of and/or reaching for food, and non-food objects; one-arm suspensions on a tyre and touching).
9.9.2. Data A nalysis

9.9.2.1. At the Individual Level

To assess the presence of a population bias in nipple preference, maternal cradling (arm and/or hand used), infant head position, maternal carrying and infant retrieval, the scores for each subject are summed for the 12 observation sessions. Based on these totals, lateral bias $(\mathrm{LB}=\mathrm{R}-\mathrm{L} / \mathrm{R}+\mathrm{L})$ scores as well as absolute value (ABS - LB) scores are calculated. Significant individual biases are assessed using a $\mathrm{z}$-score for each LB, with a $>=1.96(\mathrm{p}<0.05)$ in absolute value indicating an individual with a significant bias and a positive value reflecting a right-side bias and a negative value reflecting a left-side bias.

\subsubsection{At the Population Level}

Population biases are assessed using one-sample t-tests for each measure and the LB scores are compared to a normal distribution with a mean of zero.

\subsubsection{Results and Discussio}

In this part, we only report results obtained using the 15-min focal-dyad sampling; during analysis the number of bouts for each measure collected with 19 mother-infant dyads of olive baboons were summed across the 12 observation sessions. Depicted in Table 9.9 are the percentages of subjects classified as left- or right-sided bias based on the sign of their LB score as well as of their $\mathrm{z}$-score for each behavioural measure. Subjects with negative values were classified as left-sided and subjects with positive scores were classified as right-sided. Population-level biases for each behavioural measure were assessed using one-sample t-tests (see Table 9.9). For nipple preference and head position of the infant, the mean LB was significant (0.29 and 0.15, respectively), indicating a preference for the infant to suckle on the right and to have the head on the right as well. A Spearman correlation coefficient $[\mathrm{r}(19)=0.79, \mathrm{p}<0.0001]$, indicates a significant correlation between these two measures. However, for maternal cradling, infant retrieval; and maternal carrying, the mean LB were not significantly biased $(0.06,0.16$, and -0.04 , respectively).

One-sample t-tests for the ABS - LB measures reveal consistent asymmetries for all of the measures, with a value of 0.16 for cradling, 0.55 for nipple preference, 0.21 for head position, 0.45 for retrieval and 0.36 for carrying. Asymmetries in strength of bias were evident at a high significance level $(p<0.0001)$ for each behavioural measure: maternal cradling bias, 


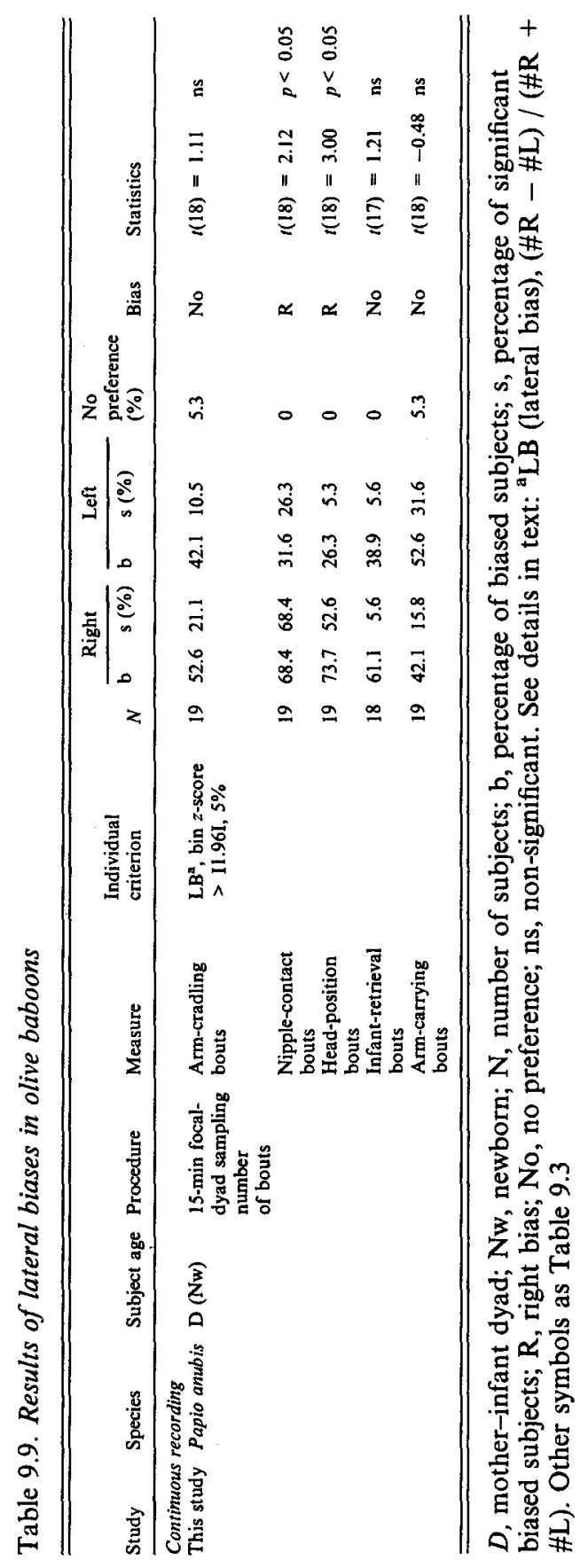

$t(18)=5.42$, nipple preference, $t(18)=12.96$, infant head position, $t(18)=8.24$, infant retrieval, $t(17)=7.17$, and maternal carrying bias $t(18)=5.83$. These significant values of $t$-tests indicate that the behaviours were not normally distributed with respect to lateral biases.

In other words, the fact that we did not find any significant mean for the LB score but significant means for the ABS - LB score reveals that even if, at the population level, non-human primates do not necessary exhibit a strong bias, most of the individuals are biased toward the right or the left side.

Our survey of the postural asymmetry patterns in human and non-human primates also indicates that it is not clear whether there are some relations between different behaviours such as maternal cradling, nipple suckling and the position of the head of the infant. Exploring the relation between, for example, head position of the infant and the hand used by the mother during cradling is possible by using a focal-dyad sampling procedure. While studies on cradling in humans mostly use instantaneous methods, Damerose and Hopkins (2001) reported a strong comparability of data from the number of bouts (scan and instantaneous) and those from the total duration and/or number of bouts (focal dyad with continuous recording). The use of a single technique should allow us to determine whether or not cradling, infant head position and nipple suckling are independent behavioural units. In particular, there was no significant positive correlation between maternal cradling and infant's head position [Spearman coefficient $r(19)=0.11, p=0.66]$ as the conclusion of Manning and Chamberlain $(1990,1991)$ would have predicted (see above).

Our procedures make it possible to combine tests with a set of different apparatuses and unprompted observations of free actions used to determine the handedness of each individual (e.g., a food-reaching task using an apparatus that forces choice with one hand; spontaneous hand preference when carrying food and other items; one-arm suspension by a tyre to establish which is the stronger arm). Moreover, the use of different types of devices allows us to record hand performance in seminatural conditions. Examples are (1) the haptic discrimination task, which establishes the more sensitive hand for tactile exploration, and (2) the sloping plane which shows which is the faster and more skilful hand.

In short, the advantage of our approach is to record, in the same subjects, both spontaneous reaching in naturalistic conditions and experimentally induced reaching in a test. Very few studies have chosen this approach in the handedness literature (but see Marchant and McGrew, 1991). Furthermore, McGrew and Marchant (1997) argue that most studies on 
the laterality of hand function focus on one-handed tasks and ignore what the other hand is (or is not) doing. In a meta-analysis of methods performed to compare studies of the laterality of functions in apes, Marchant and McGrew (1991) reported that only seven studies have tested bimanuality, using a sequential task, such as sliding a panel to align two openings, through which a food reward could then be reached (e.g. Fagot and Vauclair, 1988a, 1988b). Few studies explicitly included tasks that require the two hands to be used simultaneously and complementary with a single object (Byrne and Byrne, 1991). Moreover, the typical task for assessing laterality of functions is one-handed, non-sequential and required global rather than fine movements.

Our techniques and devices allow us to experimentally and spontaneously determine hand preference of adult females as well as that of very young infants (from the age of 3 months), and also hand performance and hand collaboration. The kind of studies in which we are engaged should lead to a better integration of research on environmental (e.g. maternal cradling, infant posture) and biological (physiological, neurological, hormonal, genetic, etc.) factors that affect the development of hand preference of the primate infant.

9.10. Conclusion

Most of the studies cited above are concerned with determining, at the population level, hand preference in human and non-human primates. In general, authors sum or average collected data distinguishing only infant and adult groups. None of the studies with prosimians, New World primates, Old World primates and great apes have yielded clear conclusions as to the effects of age on the development of manual preferences in non-human primates (for reviews, see Hook-Costigan and Rogers, 1996).

Concerning the origin of handedness, Matoba, Masataka and Tanioka (1991) propose, from their studies with marmosets, that hand preference of the infant may be genetically determined or may develop with experience, for example, through imitation of the mother's hand use. In a recent study, Dellatolas et al. (1997) suggest that manual asymmetry in humans could in fact be under the influence of. (1) biological (i.e. genetic and prenatal) factors; (2) a 'right-biased' environment; and (3) a learning phenomenon. Nonetheless, it is still not known whether and how maternal influences may affect the hand preference of an infant (Hook-Costigan and Rogers, 1996).
Thus, with respect to maternal cradling biases, Hopkins et al. (1993a) reported that maternal cradling bias correlated inversely with the infant's hand preference for simple reaching when tested at 3 years of age. In addition, another study with chimpanzees revealed the existence of a relation between mother's hand preference and the hand preference of her infant (Hopkins, Bales and Bennett, 1993). These latter authors compared the strength and the direction of hand preference between generations, parents and siblings. Their results were in favour of the existence of a hereditary component for the expression of handedness. Using the coordinated bimanual tube task to test parent and offspring chimpanzees, Hopkins (1999) suggests that the direction of hand preference is heritable, although it is unlikely that the mechanism of transmission is genetic. It could be instead that it is behavioural, with infant handedness being determined by the behaviour of the mother. Explanations of this sort include effects of: (1) maternal cradling bias (Provins, 1997); (2) intrauterine fetal position (Previc, 1991); or (3) prenatal hormonal environment (Geschwind and Galaburda, 1985). But for the ti me being, there are no strong data that can be used to support or to challenge any of these views. Further studies of the type we are conducting, which measure a number of different parameters, are needed to assess the effects of each of the abovementioned factors.

\section{References}

Altmann, J. (1974). Observational study of behavior: sampling methods. Behaviour, 49, 227-267.

Altmann, J. (1980). Baboon Mothers and Infants. Cambridge, MA: Harvard University Press.

Annett, M. (1985). Left, Right, Hand and Brain: The Right Shift Theory. Hillsdale, NJ: Lawrence Erlbaum.

Annett, M. (1995). The right shift theory of a genetic balanced polymorphism for cerebral dominance and cognitive processing. Current Psychology of Cognition, 14, 427-480.

Bard, K.A., Hopkins, W.D. \& Fort, C.L. (1990). Lateral bias in infant chimpanzees (Pan troglodytes). Journal of Comparative Psychology, 104, 309321.

Bennett, H.L., Delmonico, R.L. \& Bond, C.F. (1987). Expressive and perceptual asymmetries of the resting face. Neuropsychologia, 25, 681-687.

Bogren, L. (1984). Side preference in women and men when holding their newborn child: psychological background. Acta Psychiatrica Scandinavia, 69 newborn $13-23$.

Brazelton, T.B. (1984). Neonatal Behavioral Assessment Scale, 2nd edn. Philadelphia: Spastics International Medical Publications.

Bundy, R.S. (1979). Effects of infant head position on sides preference in adult handling. Infant Behavior and Development, 2, 355-358. 
Byrne, R.W. \& Byrne, J.M. (1991). Hand preferences in the skilled gathering tasks of mountain gorillas (Gorilla gorilla berengei). Cortex, 27, 521-536.

Campbell, R. (1978). Asymmetries in interpreting and expressing a posed facial expression. Cortex, 14, 327-342.

Caplan, P.J. \& Kinsbourne, M. (1976). Baby drops the rattle: Asymmetry of duration of grasp by infants. Child Development, 47, 532-534.

Corballis, M.C. \& Beale, I.L. (1976). The Psychology of Left and Right. Hillsdale, NJ: Lawrence Erlbaum.

Coryell, J. \& Michel, G.P. (1978). How supine postural preferences of infants can contribute towards the development of handedness. Infant Behavior and Development, 1, 245-257.

Dagenbach, D., Harris, L.G. \& Fitzgerald, H.E. (1988). A longitudinal study of lateral biases in parents' cradling and holding of infants. Infant Mental Health Journal, 9, 219-233.

Damerose, E. \& Hopkins, W.D. (2001). A comparison of scan and focal sampling procedures in the assessment of laterality for maternal cradling and infant nipple preferences in olive baboons (Papio anubis). Animal Behaviour, in press.

Damerose, E. \& Vauclair, J. (1999). Development of hand asymmetry in Olive baboons (Papio anubis): Effects of the mothers' posture and manual laterality. Folia Primatologica, 70, 208-209.

Dellatolas, G., Tubert-Bitter, P., Curt, F. \& De Agostini, M. (1997). Evolution of degree and direction of hand preference in children: methodological and theoretical issues. Neuropsychological Rehabilitation, 7, 387-399.

Dienske, H., Hopkins, B. \& Reid, A. K. (1995). Lateralization of infant holding in chimpanzees: New data do not confirm previous findings. Behaviour, 132 801-809.

Erwin, J. \& Anderson, B. (1975). Nursing behavior of infant pigtail monkeys (Macaca nemestrina): Preferences for nipples. Perceptual and Motor Skills, 592-594.

Fagot, J. \& Bard, K. A. (1995). Asymmetric grasping response in neonate chimpanzees (Pan troglodytes). Infant Behavior and Development, 18, 253-255.

Fagot, J. \& Vauclair, J. (1988a). Handedness and bimanual coordination in the lowland Gorilla. Brain, Behavior and Evolution, 32, 89-95.

Fagot, J. \& Vauclair, J. (1988b). Handedness and manual specialization in the baboon. Neuropsychologia, 26, 795-804.

Fagot, J. \& Vauclair, J. (1991). Manual laterality in nonhuman primates: A distinction between handedness and manual specialization. Psychological Bulletin, 109, 76-89.

Geschwind, N. \& Galaburda, A.M. (1985). Cerebral lateralization: Biological mechanisms, associations and pathology: 1. A hypothesis and program of research. A rchives of Neurology, 42, 428-459.

Gesell, A. \& Ames, L.B. (1947). The development of handedness. Journal of Genetic Psychology, 70, 155-175.

Harris, L.J. \& Fitzgerald, H.E. (1985). Lateral cradling preferences in men and women: Results from a photographic study. The Journal of General Psychology, 112, 185-189.

Harris, L.J., Almerigi, J.B. \& Kirsch, E.A. (2000). Side-preference in adults for holding infants: Contributions of sex and handedness in a test of imagination. Brain and Cognition, 43, 246-252.
Hatta, T. \& Koike, M. (1991). Left-hand preference in frightened mother monkeys in taking up their babies. Neuropsychologia, 29, 207-209.

Hauser, M.D. (1993). Right hemisphere dominance for the production of facial expression in monkeys. Science, 261, 475-477.

Hepper, P.G., Shahidullah, S. \& White, R. (1991). Handedness in the human fetus. Neuropsychologia, 29, 1107-1111.

Hook-Costigan, M.A. \& Rogers, L.J. (1996). Hand preferences in new world primates. International Journal of Comparative Psychology, 9, 173-207.

Hook-Costigan, M.A. \& Rogers, L.J. (1998). Lateralized use of the mouth in production of vocalizations by marmosets. Neuropsychologia, 36, 1265-1273.

Hopkins, B. \& Rönnqvist, L. (1998). Human handedness: Developmental and evolution perspectives. In The Development Sensory, Motor and Cognitive Capacities in Early Infancy: From Perception to Cognition, ed. F. Simion \& G. Butterworth, pp. 191-236. London: Psychology Press.

Hopkins, W.D. (1995). Hand preferences for a coordinated bimanual task in 110 chimpanzees (Pan troglodytes): Cross-sectional analysis. Journal of Comparative Psychology, 109, 291-297.

Hopkins, W.D. (1999). Heritability of hand preference in chimpanzees (Pan troglodytes): Evidence from a partial interspecies cross-fostering study. Journal of Comparative Psychology, 113, 307-313.

Hopkins, W.D. (2001). On the other hand: Statistical issues in the assessment and interpretation of hand preference data in nonhuman primates. International Journal of Primatology, in press.

Hopkins, W.D. \& Bard, K.A. (1995). Asymmetries in spontaneous head orientation in infant chimpanzees (Pan troglodytes). Behavioral Neuroscience, $109,808-812$.

Hopkins, W.D. \& De Waal, F.B.M. (1995). Behavioral laterality in captive bonobos (Pan paniscus): Replication and extension. International Journal of Primatology, 16, 261-276.

Hopkins, W.D. \& Parr, L.A. A multimethod assessment of laterality in carrying in humans (submitted)

Hopkins, W.D., Bales, S.A. \& Bennett A.J. (1993). Heritability of hand preference in chimpanzees (Pan). International Journal of Neuroscience, 74, 17-26.

Hopkins, W.D., Bard, K.A., Jones, A. \& Bales, S.L. (1993a). Chimpanzee hand preference in throwing and infant cradling: Implications for the origin of human handedness. Current Anthropology, 34, 786-790.

Hopkins, W.D., Bennett, A.J., Bales, S.L., Lee, J. \& Ward, J.P. (1993b). Behavioral laterality in captive bonobos (Pan paniscus). Journal of Comparative Psychology, 107, 403-410.

Jenni, D.A. \& Jenni, M.A. (1976). Carrying behavior in humans: Analysis of sex differences. Science, 194, 859-860.

Kaplan-Solms, K.L. \& Saling, M.M. (1988). Lateral asymmetry and tactile sensitivity. Perceptual and Motor Skills, 67, 55-62.

Konishi, Y., Mikawa, H. \& Suzuki, J. (1986). Asymmetrical head-turning of preterm infants: Some effects on later postural and functional lateralities. Developmental Medicine and Child Neurology, 28, 450-457.

Konishi, Y., Kuruyama, M., Mikawa, H. \& Suzuki, J. (1987). Effect of body position on later postural and functional lateralities of preterm infants. Developmental Medicine and Child Neurology, 29,751-757. 
Lacreuse, A., Fagot, J. \& Vauclair, J. (1992). Manual preferences for tactile discrimination in the baboon (Papio papio). Poster presented at the XIVth Congress of the International Primatological Society, Strasbourg, France.

Lawick-Goodall, J. van (1968). Behaviour of free-ranging chimpanzees in the Gombe Stream Reserve (Tanzania). A nimal Behavior Monographs, 1, 161311.

Lehner, P.N. (1996). Handbook of Ethological Methods, 2nd edn. Cambridge: Cambridge University Press.

Lucas, M.D., Turnbull, O.H. \& Kaplan-Solms, K.L. (1993). Laterality of cradling in relation to perception and expression of facial affect. Journal of Genetic Psychology, 154, 347-352.

MacNeilage, P.F., Studdert-Kennedy, M.G. \& Lindblom, B. (1987). Primate handedness reconsidereted. Behavioral and Brain Sciences, 10, 247-263.

Manning, J.T. (1991). Sex differences in left-side infant holding: results from family album' photographs. Ethology and Sociobiology, 12, 337-343.

Manning, J.T. \& Chamberlain, A.T. (1990). The left-side cradling preference in great apes. Animal Behaviour, 39, 1224-1227.

Manning, J.T. \& Chamberlain, A.T. (1991). Left-side cradling and brain lateralization. Ethology and Sociobiology, 12, 237-244.

Manning, J.T. \& Denman, J. (1994). Lateral cradling preferences in humans (Homo sapiens): Similarities within families. Journal of Comparative Psychology, 108, 262-265.

Manning, J.T., Heaton, R. \& Chamberlain, A.T. (1994). Left-side cradling: Similarities and differences between apes and humans. Journal of Human Evolution, 26, 77-83

Marchant, L.F. \& McGrew, W.C. (1991). Laterality of function in apes: A metaanalysis of methods. Journal of'Human Evolution, 21, 425-438.

Martin, P. \& Bateson, P. (1993). Measuring Behaviour: An Introductory Guide, 2nd edn. Cambridge: Cambridge University Press.

Matoba, M., Masataka, N. \& Tanioka, Y. (1991). Cross-generational continuity of hand-use preferences in marmosets. Behaviour, 117, 281-286.

McGrew, W.C. \& Marchant, L.F. (1997). On the other hand: Current issues in, and meta-analysis of the behavioral laterality of hand function in nonhuman primates. Yearbook of Physical Anthropology, 40, 201-232.

Michel, G.F. (1981). Right-handedness: A consequence of infant supine headorientation preference? Science, 212, 685-687.

Michel, G.F. \& Goodwin, R. (1979). Intrauterine birth position predicts newborn supine head position preferences. Infant Behavior and Development, 2, 29-38.

Nishida, T. (1993). Left nipple suckling preference in wild chimpanzees. Ethology and Sociobiology, 14, 45-52.

Porac, C. \& Coren, S. (1981). Lateral Preferences and Human Behavior. New York: Springer.

Previc, F.H. (1991). A general theory concerning the prenatal origins of cerebral lateralization in humans. Psychological Review, 98, 299-334.

Provins, K.A. (1997). Handedness and speech: A critical reappraisal of the role of genetic and environmental factors in the cerebral lateralization of function. Psychological Review, 104, 554-571.

Richards, J.L. \& Finger, S. (1975). Mother-child holding patterns: A crosscultural photographic survey. Child Development, 46, 1001-1004.
Rogers, L.J. \& Kaplan, G. (1996). Hand preferences and other lateral biases in rehabilitated orang-utans (Pongo pygmeus pygmeus). A nimal Behaviour, 51

Rogers, L.J. \& Kaplan, G. (1998). Teat preference for suckling in common marmosets: Relationship to side of being carried and hand preference. Laterality, 3, 269-281.

Rönnqvist, L. \& Hopkins, B. (1998). Head position preference in the human newborn: A new look. Child Development, 69, 13-23.

Rönnqist, L., Hopkins, B., Van Emmerik, R. \& De Groot, L. (1998). Lateral biases in head turning and the Moro response in the human newborn: are they both vestibular in origin? Developmental Psychobiology, 339-349.

Saling, M.M. \& Bonert, R. (1983). Lateral cradling preferences in female preschoolers. Journal of Genetic Psychology, 142, 149-150.

Saling, M.M. \& Cooke, W.L. (1984). Cradling and transport of infants by South African mothers: A cross-cultural study. Current Anthropology, 25, 333-335.

Saling, M.M. \& Kaplan-Solms, K. (1989). On lateral asymmetry in cradling behaviour and breast sensitivity. Current Anthropology, 30, 210-211.

Saling, M.M. \& Tyson, G. (1981). Lateral cradling preferences in nulliparous females. Journal of Genetic Psychology, 139, 309-310.

Salk, L. (1960). The effects of the normal heartbeat sound on the behavior of the new-born infant: Implications for mental health. World Mental Health, 12, 168-175.

Salk, L. (1962). Mother's heartbeat as an imprinting stimulus. Transactions of the New York Academy of Sciences, 24, 753-763.

Salk, L. (1970). The critical nature of the post-partum period in the human for the establishment of the mother-infant bond: A controlled study. Nervous System, 31, 110-113.

Salk, L. (1973). The role of the heartbeat in the relations between mother and infant. Scientific American, 228, 24-29.

Sieratzki, J.S. \& Woll, B. (1996). Why do mothers cradle babies on their left? Lancet, 347, 1746-1748.

Souza-Godeli, M.R. (1996). Lateral cradling preferences in children. Perceptual and Motor Skills, 83, 1421-1422.

Tanaka, I. (1989). Change of nipple preference between successive offspring in Japanese macaques. A merican Journal of Primatology, 18, 321-325.

Tanaka, I. (1997). Parity-related differences in suckling behavior and nipple preference among free-ranging Japanese macaques. A merican Journal of Primatology, 42, 331-339.

Thompson, A.M. \& Smart, J.L. (1993). A prospective study of the development of laterality: Neonatal laterality in relation to perinatal factors and maternal behavior. Cortex, 29, 649-659.

Tomaszycki, M., Cline, C., Griffin, B., Maestripieri, D. \& Hopkins, W.D. (1998). Maternal cradling and infant nipple preferences in rhesus monkeys (Macaca mulatta). Developmental Psychobiology, 32, 305-312.

Turnbull, O.H. \& Lucas, M.D. (1991). Lateral cradling preferences in males: The relationship to infant experience. Journal of Genetic Psychology, 152, 375-376

Turnbull, O.H. \& Matheson, E.A. (1996). Left-sided cradling. Lancet, 348, 691 692.

Ward, J.P. \& Hopkins, W.D. (eds) (1993). Primate Laterality: Current Behavioral Evidence of Primate A symmetries. New York: Springer Verlag. 
Weiland, H. (1964). Heartbeat rhythm and maternal behavior. American Academy of Child Psychiatry, 3, 161-164.

Weiland, H. \& Sperber, Z. (1970). Patterns of mother-infant contact: The

significance of lateral preference. Journal of Genetic Psychology, 117, 157-165.

Weinstein, S. (1963). The relationship of laterality and cutaneous area to breast sensitivity in sinistrals and dextrals. American Journal of Psychology, 76, 475479.

Westergaard, G.C., Byrne, G. \& Suomi, S.J. (1998). Early lateral bias in tufted capuchins (Cebus apella). Developmental Psychobiology, 32, 45-50.

Wind, J. (1982). On child transport in Sri Lanka. Current Anthropology, 23, 333. 